\title{
Relación entre la posición del atacante de primer tiempo y del colocador y su influencia en la zona de ataque en voleibol masculino de élite
}

\author{
Relationship between first tempo attacker and setter's position and its \\ influence on the attack zone in elite male volleyball
}

\section{Autora: Ma Isabel Sapena Peiró}

\author{
Tutor: Aurelio Ureña Espá
}

Departamento de Educación Física y Deportiva

Co-Tutor: José Manuel Benítez Sánchez

Departamento de Ciencias de la Computación e Inteligencia Artificial
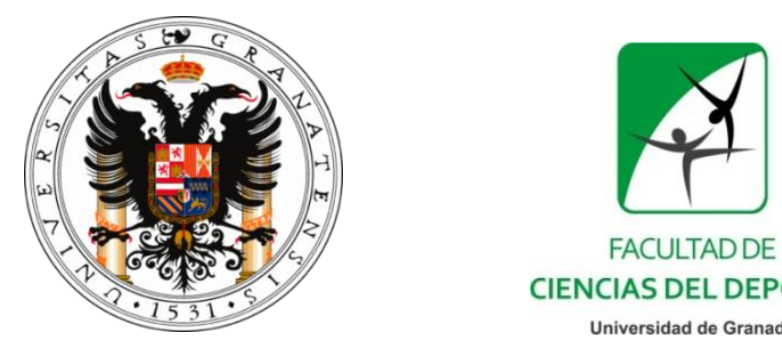

FACULTADDE

CIENCIAS DEL DEPORTE

Universidad de Granada

Máster de Investigación en Actividad Física y Deporte Trabajo Fin de Máster

Departamento de Actividad física y Deportiva

Facultad de Ciencias del Deporte

Universidad de Granada 


\section{Índice}

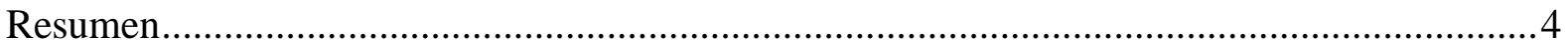

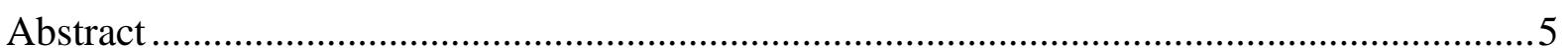

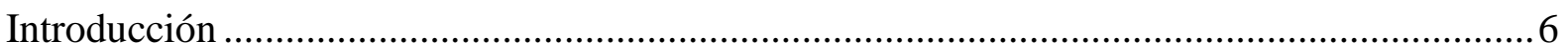

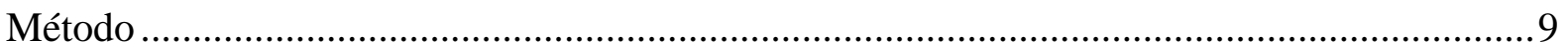

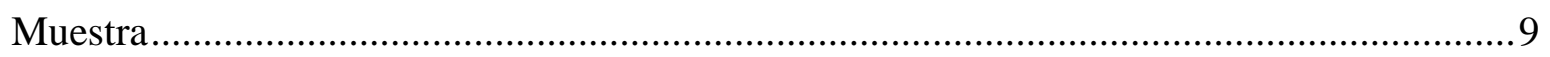

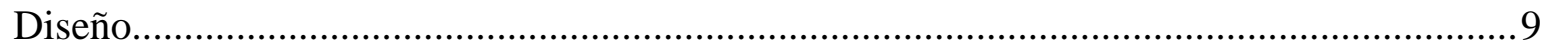

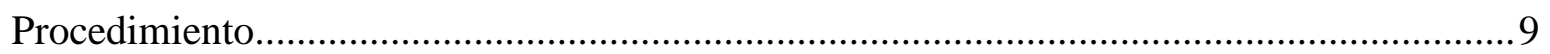

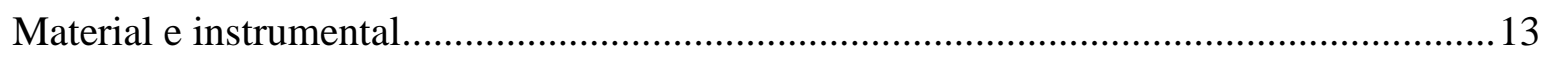

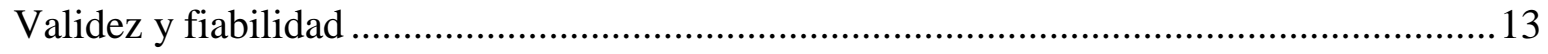

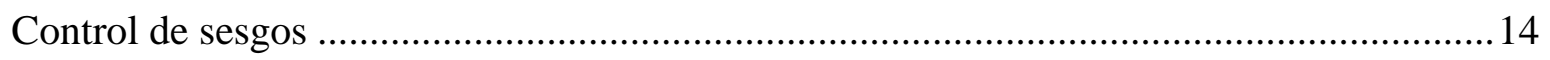

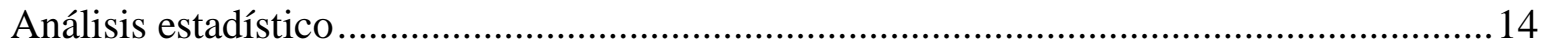

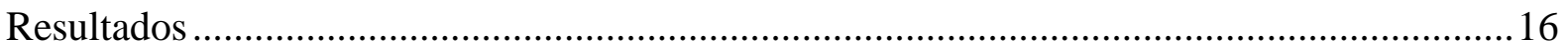

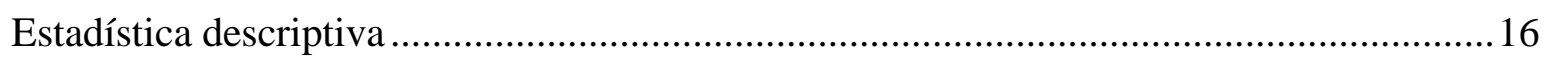

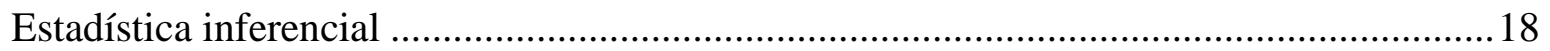

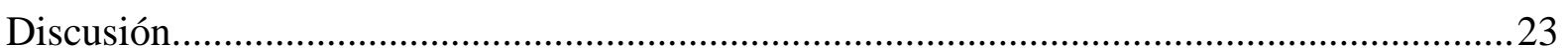

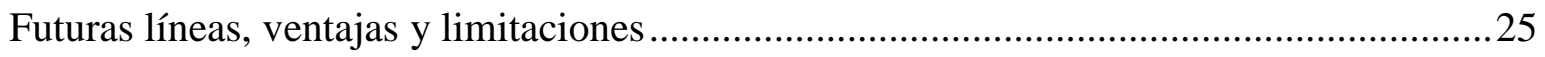

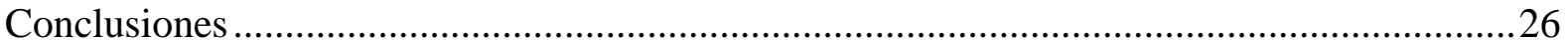

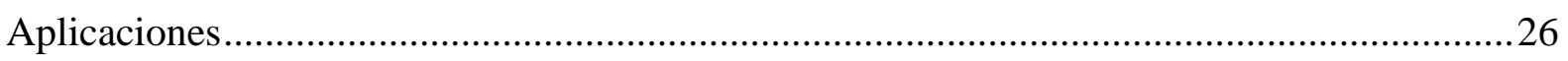

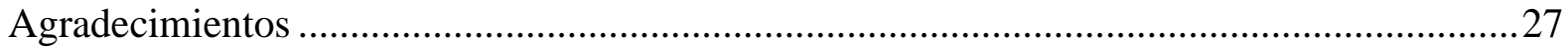

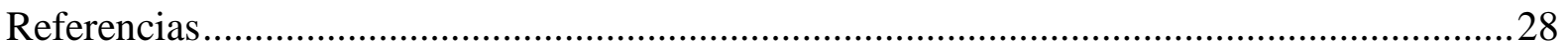

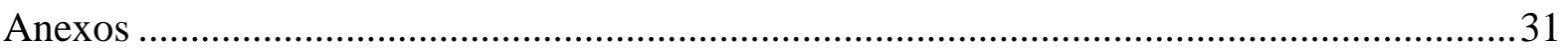




\section{Resumen}

El objetivo principal de este estudio fue determinar si las relaciones espaciales entre el colocador, el atacante de primer tiempo y el atacante de segundo tiempo constituyen predictores de la zona de finalización de ataque en el Complejo I de juego en equipos de élite masculinos. Un total de 3936 jugadas correspondientes a veintitrés partidos del Campeonato del mundo de voleibol masculino de 2010 fueron analizadas mediante un sistema de categorías, recurriendo a la metodología observacional. Las variables medidas fueron Disponibilidad del atacante de primer tiempo, Tipo de ataque y Latitud del atacante de primer tiempo, del colocador y del atacante de segundo tiempo. A partir de estas últimas se calculó el Pasillo de ataque de segundo tiempo y la Distancia entre jugadores. Los resultados de este estudio sugieren que existe una relación muy significativa $(p<0.01)$ entre la posición del atacante de primer tiempo y la del colocador, independientemente de si ocurre o no ataque de primer tiempo. Mediante el árbol de clasificación empleado se observó que la posición del atacante de primer tiempo varía acorde con la del colocador, normalmente a una distancia de uno o dos metros por delante. Además, la variable Distancia del colocador al atacante de primer tiempo aparece como principal predictora del pasillo de ataque de segundo tiempo. El presente estudio contribuye a una visión dinámica en la relación espacial entre los jugadores, a través de la cual se pudo predecir la zona de finalización de ataque, siendo esta información de especial relevancia en el contexto real del juego en voleibol.

Palabras clave: posición, atacante de primer tiempo, zona de ataque, Complejo I, voleibol. 


\begin{abstract}
The purpose of this study was to determine whether spatial relationships between the setter, the first tempo attacker and the second tempo attacker can predict the attack zone in Complex I in elite male volleyball. A total amount of 3936 rallies corresponding to 23 matches of the Men's World Championship 2010 were analyzed following a category system, recurring to observational methodology. Measured variables were Availability of the first tempo attacker, Attack type and Latitude of the first tempo attacker, setter and second tempo attacker. From the Latitude, the following variables were calculated: Second tempo attack lane and Distance between players. Results suggest that a relationship with high level of significance $(p<0.01)$ exists between the first tempo attacker position and setter's position, regardless of the occurrence of a first tempo attack. By means of the classification tree, it was observed that the first tempo attacker position was modified according to setter's position, normally with a distance of one or two metres ahead of him. Furthermore, the variable Distance from setter to first tempo attacker emerged as the main predictor of the second tempo attack lane. This study provides a dynamical perspective about the spatial relationship between players, which contributed to predict the attack zone, being this information of great interest in the real context in volleyball.
\end{abstract}

Key words: position, first tempo attacker, attack zone, complex I, volleyball. 


\section{Introducción}

El análisis del rendimiento deportivo constituye un ámbito de estudio de gran relevancia en los deportes de interacción, ya que permite comprender los factores que rigen el juego en los equipos de élite (Hugues y Bartlett, 2002). Para el análisis del rendimiento deportivo, una de las herramientas objetivas que se suele emplear es el análisis notacional, el cual ha supuesto un aumento en la rapidez, precisión, eficiencia en el registro y agrupación de datos, dotando de una mayor comprensión de los patrones del juego, y una evaluación más precisa de los equipos y jugadores (Peña, Rodríguez-Guerra y Serra, 2013).

En voleibol, el estudio de indicadores de rendimiento resulta de especial interés dado que durante el desarrollo del juego se dan interacciones de forma continua entre los equipos rivales, lo cual conlleva a la aparición de patrones únicos de juego (Afonso, Esteves, Araújo, Thomas y Mesquita, 2012). Así pues, cabe destacar que este deporte se identifica por una característica propia: la secuencialidad de eventos durante el juego. Este rasgo permite estudiar la dependencia entre la eficacia de acciones secuenciales, es decir, cómo las acciones previas influyen sobre las posteriores, así como el impacto que dicha dependencia tiene a la hora de determinar el resultado final de cada jugada (Lames y McGarry, 2007; Mesquita, 2005).

Para un análisis más concreto del rendimiento, Costa et al. (2011a) sugieren que existe una necesidad de estudiar las características del juego en función de los distintos complejos de juego. Para comprender este último concepto, Ureña (1998) habla de cómo la sucesión de contactos con el balón da lugar a trayectorias que a su vez protagonizan las fases o complejos de juego, de tal modo que los equipos se encuentran alternativamente en situación de ataque y de defensa. Esa necesidad de analizar cada complejo de juego separadamente se justifica por los rasgos propios que presentan las acciones ofensivas en cada uno de los dos grandes complejos de juego (Complejo I o K1 y Complejo II o K2), específicamente en función de las características de la colocación, el tiempo de ataque, los sistemas defensivos adoptados por el oponente y la zona de ataque (Palao, Santos, y Ureña, 2007). En los últimos años ha habido un interés creciente por analizar el K1 o fase de ataque, definido por Bertucci (1979) como la fase en que un equipo recibe el saque y ejecuta de forma secuencial las acciones de recepción, colocación y ataque. Así mismo, diversos autores (Castro y Mesquita, 2008; Castro, Souza y Mesquita 2011) consideran el K1 como la fase del juego más predecible y relativamente estable con baja interferencia contextual, ya que depende solamente de una acción directa del oponente: el saque.

Entre las acciones de voleibol, se ha demostrado que el ataque constituye la acción que presenta una mayor correlación con el éxito, independientemente de la fase del juego (Castro y Mesquita, 2008; Palao, Santos y Ureña, 2004). En este sentido, cabe destacar la variable tiempo de ataque, cuya importancia ha sido demostrada por diversos estudios dado su gran poder predictivo (Afonso y Mesquita, 2011; Marcelino, Afonso, Moraes y Mesquita, 2008; Nikos y Elissavet, 2011). Así, aquellos tiempos de ataque que más se asocian con el éxito son los más rápidos, (Asterios, Kostantinos, Athanasios y Dimitrios, 2009; Castro y Mesquita, 
2008; Costa, Barbosa y Gama, 2013; Costa et al., 2011a; Marcelino, Cesar, Afonso y Mesquita, 2008; Palao et al., 2007; Zetou, Moustakidis, Tsigilis, y Komninakidou, 2007) incluyendo los ataques de primer tiempo (el atacante salta durante la colocación o justo después, posiblemente dando un paso después de la colocación) y de segundo tiempo (el atacante da dos o tres pasos después de la colocación) (Afonso, J. et al., 2010). Estos resultados se ven reflejados en el estudio de Costa, Mesquita, Greco, Ferreira y Moraes (2010), quienes al analizar la relación entre el tiempo de ataque y la eficacia del ataque, observaron que los ataques más rápidos favorecían ganar el punto, confirmando así la tendencia actual en voleibol de que el juego sea cada vez más rápido. Dicha asociación se justifica porque este tipo de ataques crean un déficit de tiempo para el oponente que le impide organizar su sistema defensivo correctamente (Afonso, Mesquita, Marcelino y Silva, 2010; Asterios et al., 2009; Palao et al., 2007).

Para comprender cómo se consigue el punto en ataque, es vital considerar las acciones previas así como las posteriores (Castro, Souza y Mesquita, 2011). Así pues, si tenemos en cuenta que la primera acción del K1 es la recepción, resulta lógico pensar que el rendimiento en dicha acción va a determinar el rendimiento de las acciones posteriores (colocación y ataque). En este sentido, en el estudio de Zetou et al. (2007) se observó que cuando el receptor realizaba una recepción perfecta, el colocador era capaz de colocar un ataque de primer tiempo ya que disponía de todas las opciones de decisión (Palao, Santos y Ureña, 2005). Dado que dicho ataque constituye el predictor más determinante de éxito del equipo en el K1 (Asterios et al., 2009), Zetou et al. (2007) concluyeron que el equipo en dicha fase del juego intenta ganar punto mediante un primer ataque directo haciendo uso de un juego ofensivo y efectivo. Ello se justifica porque en esta fase del juego se dan condiciones más favorables para organizar ataques más rápidos (Castro et al., 2011; Castro y Mesquita, 2008). Así mismo, Costa et al. (2013) y Nikos y Elissavet (2011), concluyeron que una recepción eficaz permite mejores condiciones de finalización de la jugada, confirmando la alta influencia existente entre la calidad de la recepción y la capacidad ofensiva del ataque (Costa, Mesquita, Greco, Ferreira y Moraes, 2011b; Ureña, 1998). Por otro lado, estudios como el de Bergeles, Barzouka y Nikolaidou (2009) también evidencian la relación entre la eficacia de la colocación y la eficacia del ataque, ya que un mayor rendimiento en la primera acción implica un mejor rendimiento en la segunda.

En base a la asociación que se ha demostrado entre el tiempo de ataque y el éxito, resulta fundamental que el atacante de primer tiempo esté eficazmente disponible para que el colocador pueda jugar un ataque rápido, lo cual ha sido ya evidenciado por autores como Afonso et al., 2010. Esto implica que haya una adecuada relación espacial entre el colocador, el atacante de primer tiempo y el balón, así como un timing preciso de las acciones de ambos jugadores (Afonso et al., 2010). En este sentido, en el estudio de Ureña (1998), se afirma que existe una relación entre el rendimiento en recepción, la disponibilidad del atacante y el posterior rendimiento en ataque en el $\mathrm{K} 1$.

En cuanto a la posición del central, Marcelino et al. (2014) observaron que esta variable se presenta como una de las más determinantes para predecir el ataque, poniendo así de 
manifiesto la relevancia estratégica del central. Estos autores comprobaron que en casi un $60 \%$ de las jugadas el atacante de primer tiempo se movió cerca del colocador, y sólo en un $16.4 \%$ lo hizo lejos del colocador. Igualmente observaron que el atacante de primer tiempo atacaba con más frecuencia cuando el colocador estaba en la zona ideal de colocación. En otros estudios como el de Costa et al. (2010) o Marcelino et al. (2014) se observó una mayor frecuencia de ataques de primer tiempo en las zonas más céntricas de la red (zona 3). Además de constatarse la relación de dependencia entre la posición del colocador y del atacante, igualmente se ha evidenciado la asociación entre la posición del colocador y el rendimiento del ataque (Afonso y Mesquita, 2011).

En referencia al ataque de segundo tiempo, Afonso, Mesquita y Palao (2005) demostraron que se trata del tiempo de ataque más utilizado en la fase de recepción. Además, según Costa et al. (2013), los ataques de segundo tiempo se asocian con ganar punto. Castro y Mesquita (2008), en su estudio refuerzan la tendencia en la utilización del ataque de segundo tiempo, confirmando un aumento en la velocidad de las maniobras ofensivas de los equipos, así como un aumento en la eficacia del ataque. Así mismo, cuando los primeros tiempos son ejecutados con alguna combinación de ataque, esto es cuando más de un atacante participa en la construcción ofensiva, las posibilidades de ganar punto aumentan (Marcelino et al., 2008).

Por tanto, los objetivos de este estudio fueron: (1) determinar si existe una relación entre la posición del atacante de primer tiempo respecto al colocador y el pasillo en el que se ejecuta el ataque de segundo tiempo , (2) comprobar si se da una asociación entre la posición del atacante de primer tiempo respecto al atacante de segundo tiempo y el pasillo en que ocurre el ataque de segundo tiempo, y (3) en caso de que existan tales relaciones, extraer las reglas de asociación que se pueden deducir acerca del comportamiento ofensivo de los equipos en situaciones de $\mathrm{K} 1$ en las que el atacante central está disponible. 


\section{Método}

\section{Muestra}

Se analizaron un total de 87 sets correspondientes a 23 partidos del Campeonato del Mundo de voleibol masculino de 2010 de la Federación Internacional de voleibol, disputado en Italia. Para asegurar la competitividad y el alto nivel de los participantes, todos los partidos seleccionados se correspondían con la fase final del campeonato, la cual estuvo compuesta por un total de 78 partidos. Por tanto, la muestra seleccionada corresponde a un $29 ' 48 \%$ del total de los partidos. En dicha fase los equipos con menos partidos jugados acumularon 3 partidos y los finalistas hasta 5. Para el presente estudio se seleccionaron aleatoriamente para cada selección entre 3 y 4 partidos.

La muestra representó a un total de 12 selecciones nacionales. Los equipos analizados fueron Alemania, Argentina, Brasil, Bulgaria, Cuba, España, Francia, Italia, República Checa, Rusia, Serbia y Estados Unidos.

Se observaron un total de 3936 jugadas, de las cuales se registraron 2335 jugadas con disponibilidad del atacante de primer tiempo.

\section{Diseño}

Se trata de un estudio descriptivo en el que se empleó metodología observacional, dada la naturaleza predictiva del estudio y la necesidad de preservar las condiciones naturales de la conducta, su contexto y su validez externa.

El tipo de diseño empleado fue de seguimiento, ya que se observaron varios partidos con el objetivo de poder discriminar conductas estables en los sujetos de la muestra (equipos) más allá de la circunstancia puntual de un partido; nomotético, ya que el objetivo pretendió generalizar los resultados a la población estudiada. Y por último, es de tipo multidimensional, debido a la naturaleza compleja de las conductas analizadas.

\section{Procedimiento}

En primer lugar, del total de 3936 jugadas que componen los 23 partidos seleccionados, se seleccionaron solamente aquellas jugadas en las que el central del equipo en K1, se mostraba eficazmente disponible para ejecutar un ataque rápido, ya sea simulando un ataque rápido por delante (cerca o lejos) o detrás del colocador (Afonso et al., 2010). Esta variable la denominamos Disponibilidad del atacante de primer tiempo, y se trata de una variable dicotómica.

Así mismo, resulta necesario destacar aquellas situaciones del $\mathrm{K} 1$ que han sido excluidas:

- Situaciones en que el colocador se ve obligado a colocar con un pase de antebrazos.

- Situaciones en que el colocador cometa falta en la acción de colocación. 
- Situaciones en que el colocador se ve obligado a colocar con una sola mano por encima del borde superior de la red.

- Cualquier situación en que la colocación sea ejecutada por un jugador distinto al colocador.

Las variables principales empleadas para este estudio han sido:

\section{Tipo de ataque:}

En función del jugador que realiza el ataque y el tiempo de ataque. El nivel de medida de esta variable es nominal. Se distinguen tres niveles:

- Ataque del colocador (0). El balón es atacado por el colocador.

- Ataque de primer tiempo (1): el atacante salta durante la colocación o justo después, posiblemente dando un paso después de la colocación (Afonso, J. et al., 2010).

- Ataque de segundo tiempo (2): el atacante da dos o tres pasos después de la colocación (Afonso, J. et al., 2010).

\section{Latitud:}

La latitud se define como la zona (columna o pasillo) en que se ubica el jugador en cuestión, partiendo desde el lado externo izquierdo de la pista hasta el lado externo derecho. Se distinguen 10 niveles de respuesta para la variable Latitud $(0,1,2,3,4,5,6,7,8,9,10)$, partiendo de las zonas de ataque propuestas por Coleman (1972). El nivel de medida de esta variable es de tipo ordinal.

Ante cualquier situación de duda a la hora de tomar los registros, se estableció un criterio principal, según el cual siempre se registraba la celda más cercana a la zona 6 para las tres variables de latitud. La elección de dicha zona como referencia se ha realizado partiendo de lo propuesto por Beal (1992), quién afirmó que la zona 6 es la posición más común del colocador. Si no se observa ninguno de los dos pies del jugador en cuestión, se registrará la zona que corresponda a la proyección de su cuerpo.

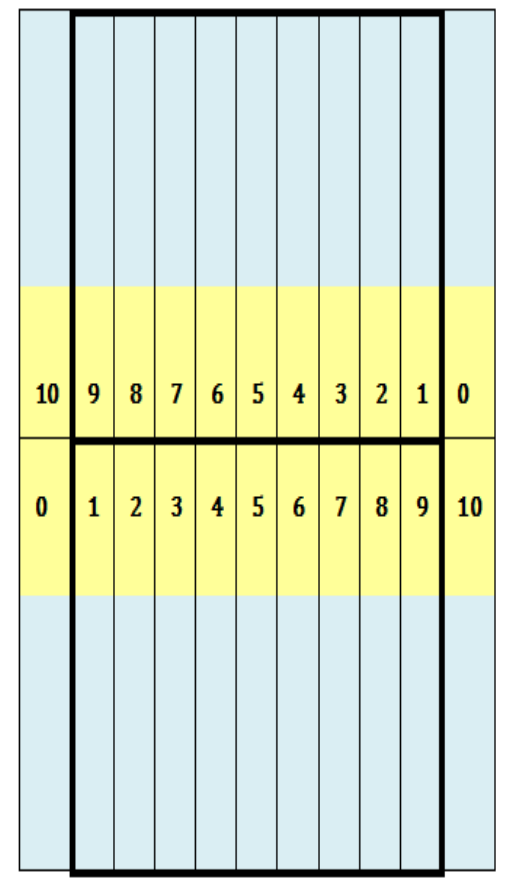

Figura 1. Zonas del campo (Latitud). 


\subsection{Latitud del colocador}

El momento en que se registró la zona donde se ejecuta la colocación siempre fue cuando el colocador ejecuta el último apoyo antes de realizar la colocación o el salto para la colocación.

Entre las situaciones posibles cabe decir que la colocación puede ser en salto o no. En el primer caso se registró la zona del último apoyo antes de realizar el salto para la colocación. En el segundo caso, se registró la zona del último apoyo antes de realizar la colocación. Se pueden dar dos situaciones:

- Que el colocador tenga ambos pies en apoyo justo antes del salto o de la colocación. En dicho caso se siguió el criterio principal de zona 6 ya explicado. Si dicho pie se ubicaba entre dos zonas, se seguía de nuevo el mismo criterio.

- Que el colocador tenga un solo pie en apoyo justo antes del salto o de la colocación. En este caso se escogió dicho pie, y si éste estaba situado entre dos zonas se siguió de nuevo el criterio de zona 6.

\subsection{Latitud del atacante de primer tiempo o central}

El momento de registro siempre fue el del último apoyo de la carrera del atacante antes del salto. Esto es, se registró la zona en que se ubica dicho pie.

En esta variable podemos distinguir dos situaciones: cuando sí hay ataque de primer tiempo y cuando no hay ataque de primer tiempo. Para ambos casos se registró la ubicación del central. Igualmente, ante cualquier situación de duda (pie entre dos celdas) se siguió el criterio de zona 6 .

\subsection{Latitud del atacante de segundo tiempo}

El momento de registro siempre fue el del último apoyo de la carrera del atacante antes del salto. Esto es, se registra la zona en que se ubica dicho pie.

A partir de las variables de Latitud se crearon las siguientes variables:

\section{Pasillo Ataque de segundo tiempo}

Esta variable es de tipo nominal. Se define como el pasillo en el que se realiza el ataque de segundo tiempo. Esta variable se creó a partir de la variable Latitud del atacante de segundo tiempo, uniendo distintas categorías para crear tres niveles de respuesta:
a. Zona 4: Latitud 0, 1 y 2
b. Pasillo Central: Latitud 3, 4, 5, 6 y 7
c. Zona 2: Latitud 8, 9 y 10 


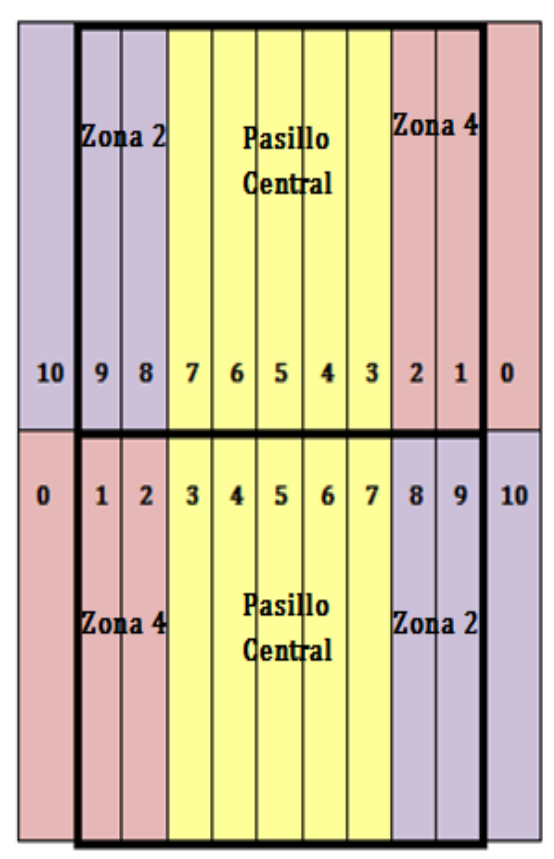

Figura 2. Pasillos de ataque de segundo tiempo.

\section{Distancia}

Partiendo de las variables Latitud descritas, se calculó la distancia entre las posiciones de los jugadores, medida en casillas o celdas que corresponden cada una de ellas a un metro de ancho en la pista de voleibol.

\subsection{Distancia del colocador al atacante de primer tiempo (Distancia Col-1T)}

Distancia entre el colocador y el atacante de primer tiempo. Calculada restando el valor de Latitud del atacante de primer tiempo al valor de Latitud del colocador.

\subsection{Distancia del atacante de primer tiempo al atacante de segundo tiempo} (Distancia $1 T-2 T)$

Distancia entre el atacante de primer tiempo y el atacante de segundo tiempo. Calculada restando el valor de Latitud del atacante de segundo tiempo al valor de Latitud del atacante de primer tiempo.

El nivel de medida de las dos variables Distancia es ordinal, obteniendo valores desde 8 hasta +9 . Cuando el valor obtenido es negativo, significa que el segundo jugador está por detrás del primero. Por el contrario, si el valor obtenido es positivo, significa que el segundo jugador está por delante del primero. Un ejemplo con la variable Distancia Col-1T sería el siguiente: si el jugador central (Latitud $1^{\circ}$ Tiempo) está en zona 7 y el colocador (Latitud Colocador) está en zona 6, entonces el valor de la distancia entre ambos es -1, por lo que el central está detrás del colocador. 


\section{Material e instrumental}

Para el registro de los datos se empleó el software de análisis observacional aplicado al voleibol VASports (versión 1.0.75). El desarrollo de este software se encuadra dentro del proyecto financiado por el Ministerio de Ciencia e Innovación, denominado "Sistema Mas Vb de Evaluación Competitiva y Orientación Técnica para la Superliga Española de Voleibol" (DEP2011-27503), que da marco a este trabajo.

Cabe destacar que se ha incorporado en dicho software una rejilla que delimita cada una de las zonas del campo que se han registrado. Dicha rejilla se ajusta perfectamente a la pista de voleibol, independientemente de la orientación y ángulo de la cámara.

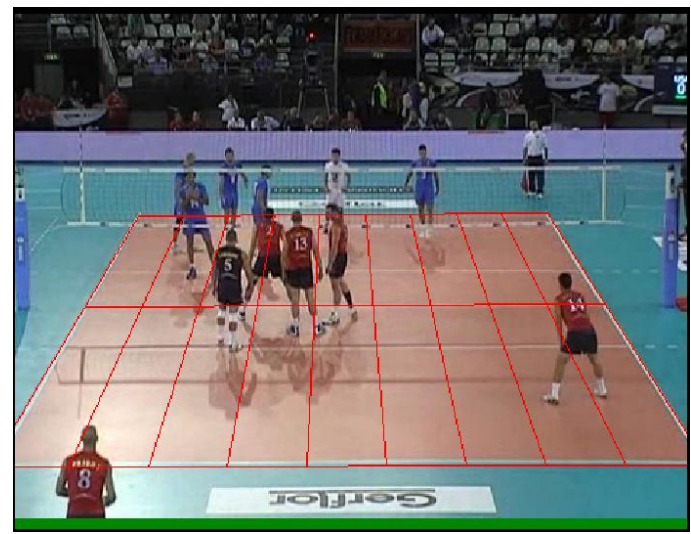

Figura 3. Imagen de vídeo en software VASports con la rejilla.

\section{Validez y fiabilidad}

El instrumento de registro empleado aportó la validez necesaria al estudio, a través del sistema de categorías desarrollado para cada una de las variables, en el que los niveles generados se apoyan en otros autores, pero también incluye otros propios. Además, las condiciones de exhaustividad y mutua exclusividad que cumple el sistema de observación elaborado, determinan que todas las manifestaciones de la conducta objeto de estudio se encuentren representadas (Anguera, Blanco, Losada y, Hernández, 2000).

Tabla 1: Fiabilidad inter-observador e intra-observador.

\begin{tabular}{lll}
\hline Cohen's Kappa & Inter-observer & Intra-observer \\
\hline Disponibilidad atacante $1^{\circ}$ tiempo & 0.948 & 0.942 \\
\hline Latitud Colocación & 0.858 & 0.870 \\
\hline Latitud Ataque $\left(1^{\circ}\right.$ y $2^{o}$ tiempo $)$ & 0.893 & 0.917 \\
\hline
\end{tabular}

Para calcular la fiabilidad se seleccionaron de forma aleatoria un $10 \%$ del total de las acciones (Tabachnick y Fidell, 2011). Se calcularon los valores Kappa (Cohen, 1960) para las variables Disponibilidad del atacante de primer tiempo, Latitud Colocación y Latitud del ataque (incluyendo en esta última Latitud del atacante de $1^{\circ}$ tiempo y Latitud del atacante de 
$2^{o}$ tiempo). Para la fiabilidad interobservador e intraobservador se obtuvieron valores por encima del 0.75 propuesto por Fleiss (2003).

Este estudio cuenta con la aprobación del Comité de Ética en Investigación Humana de la Universidad de Granada, incluido en el CD adjunto.

\section{Control de sesgos}

El sesgo de reactividad se puede considerar inexistente dada la alta frecuencia con la que los jugadores de máximo nivel son grabados en sus partidos, tanto por personal externo (medios de comunicación) como interno (equipos técnicos con el objetivo de analizar el juego). Además, las grabaciones se obtienen tras los campeonatos, sin que los que participantes tengan ninguna información sobre objetivos de cualquier análisis que se pueda hacer a posteriori.

La expectancia podría ser una limitación del estudio, al haber actuado como observador el propio investigador. No obstante, la exhaustividad del sistema de categorías no da lugar a la interpretación subjetiva de las acciones, como así queda demostrado en los análisis de fiabilidad inter e intraobservador.

La grabación de los partidos fue realizada desde una posición superior a la pista, con un plano que abarcaba la totalidad de ésta, sin modificación de su posición o imagen y sin cortes durante la filmación, evitando así errores de procedimiento.

\section{Análisis estadístico}

Para el tratamiento descriptivo (univariante) de los datos se empleó un análisis de frecuencias y porcentajes, junto con la respectiva representación gráfica mediante diagramas de sectores, de barras y de caja.

Para determinar si existía asociación (bivariante) entre las variables se llevó a cabo la técnica inferencial de correlación no paramétrica, dada la naturaleza ordinal de las variables, considerando como significativos aquellos resultados con $p<0.05$. Así mismo, se calculó el tamaño del efecto para dichas correlaciones mediante el coeficiente de correlación Rho de Spearman. Estos análisis se ejecutaron para las variables de Latitud y Distancia.

Por último, para el análisis multivariante se hicieron pruebas con distintos modelos de árboles de clasificación (entre ellos algunos de los más utilizados y que provee $\mathrm{R}$, como son ctree, evtree, rpart, corelearn...), empleando como definitivo el árbol Evolutionary Learning of Globally Optimal Trees (EVTREE) (Grubinger, Zeileis, y Pfeiffer, 2014). Se optó por este árbol por dos razones principales. En primer lugar, este modelo asumió como la variable más predictora o nodo raíz la Latitud Col_1T, en la cual se centra principalmente el interés de este estudio. En segundo lugar, la simplicidad en las reglas que genera este árbol conlleva una sencillez en la comprensión de dichas reglas y su consecuente transferencia al contexto real 
del problema. Y en tercer lugar por resultar una clasificación muy buena del modelo tras el proceso de entrenamiento

Así mismo, a partir de los índices de calidad del modelo EVTREE, tras realizar un estudio comparativo entre los diferentes modelos testeados, ha resultado ser el mejor valorado. Para comprobar la calidad y la fiabilidad de los resultados de clasificación se ha realizado Validación Cruzada 10-fold sobre cada uno de los modelos de árboles y conjunto de datos. Los resultados de calidad de clasificación de todos los Folds de cada algoritmo han sido promediados para obtener el porcentaje medio de acierto de cada modelo. En cuanto a la semilla aleatoria utilizada para generar el árbol, se recurrió a set.seed (34423425), la cual permite siempre obtener los mismos resultados.

Para los análisis univariante y bivariante el instrumento estadístico utilizado fue el paquete estadístico SPSS 20 para Windows. Para el análisis multivariante y algunas de las gráficas se empleó el software de programación R i386 3.0.3 para Windows, junto con el entorno de programación RStudio. Las librerías de R que se han utilizado han sido evtree, ctree, rpart, CORELearn, tree y randomforest. 


\section{Resultados}

\section{Estadística descriptiva}

La variable Disponibilidad del atacante de primer tiempo viene representada en el diagrama de sectores de la Figura 4, donde se observan los porcentajes de frecuencias para cada categoría. En un $59.32 \%$ de los casos ocurrió situación de K1 con disponibilidad del atacante de primer tiempo, y en un $40.68 \%$ de los casos no ocurrió dicha situación.

Del mismo modo, la Figura 5 muestra el porcentaje de casos para la variable Tipo de ataque, donde se puede observar un claro predominio de ataques de segundo tiempo (69.68\%), seguido de ataques de primer tiempo (28.39\%). El porcentaje de ataques del colocador refleja los pocos casos ocurridos para dicha categoría (1.93\%).

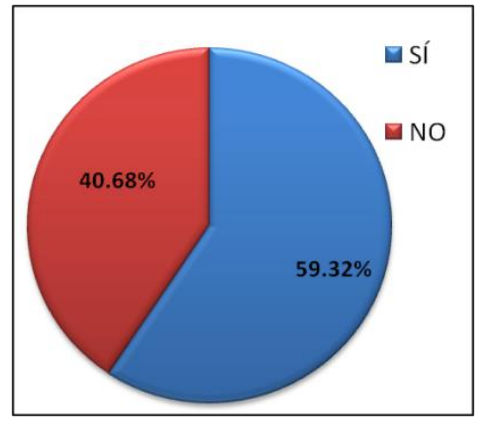

Figura 4. Porcentaje de casos para la variable Disponibilidad del atacante de primer tiempo $(\mathrm{N}=3936)$.

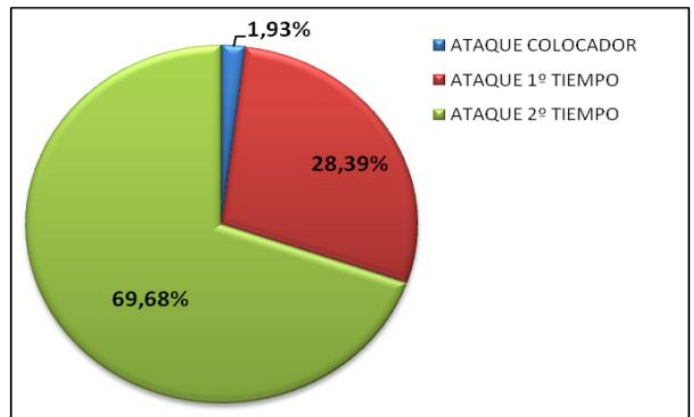

Figura 5. Porcentaje de casos para la variable Tipo de Ataque $(\mathrm{N}=2335)$.

Tanto para la variable Pasillo Ataque de segundo tiempo como para las variables Latitud, a partir de los diagramas de sectores y de barras respectivamente, se procedió a representar gráficamente sobre el campo de voleibol los porcentajes para cada categoría, con el propósito de facilitar la interpretación de los resultados en el contexto real del estudio. Así pues, en la Figura 6 se observan los porcentajes para la variable Pasillo Ataque de segundo tiempo, donde destaca el alto porcentaje de ataques en la Zona 4 (46.83\%), seguido de la Zona $2(40.20 \%)$ y en último lugar el Pasillo Central con un $12.97 \%$ de casos.

En la figura 7 se observan las frecuencias en porcentaje para las tres variables de latitud. La variable Latitud Colocador acumuló la mayoría de casos en las categorías centrales, principalmente en la Zona 5 (18.3\%), Zona 7 (25.1\%) y Zona 6, con casi la mitad de los casos (40.3\%). La variable Latitud atacante primer tiempo acumuló la mayoría de casos en la Zona 3 (19.1\%), Zona 4 (27.7\%) y Zona 5 (27.2\%). Por otro lado, se observó un comportamiento totalmente distinto en la variable Latitud atacante segundo tiempo, ya que la mayoría de casos se concentraron en sus extremos: Zonas 0 y 1 con un $46.1 \%$ de los casos, y Zonas 9 y 10, con un porcentaje para ambas de 39.6\%. 


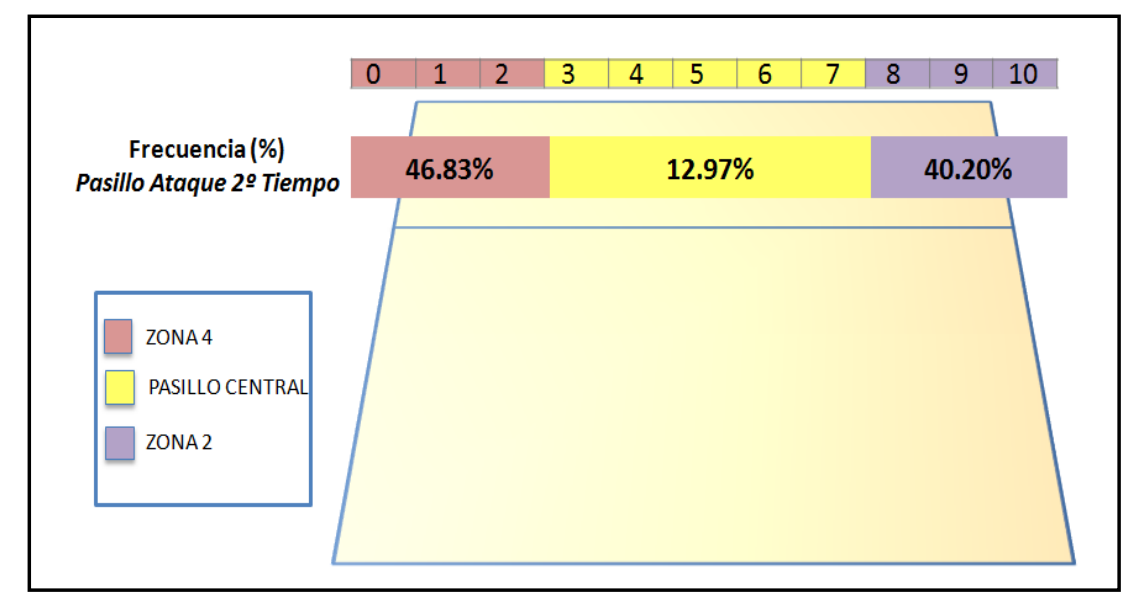

Figura 6. Representación gráfica del porcentaje de casos para la variable Pasillo Ataque de segundo tiempo $(\mathrm{N}=1627)$.

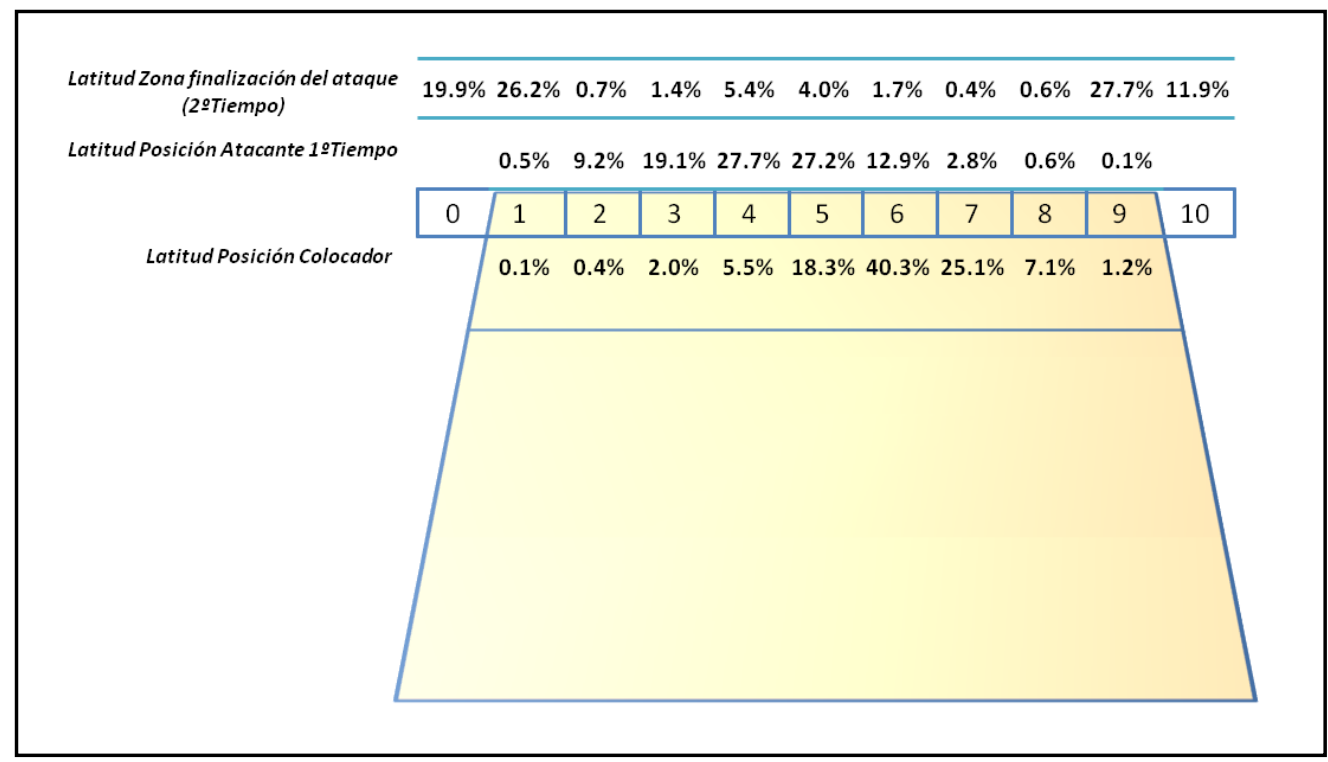

Figura 7. Distribución de casos de la latitud en la posición del colocador, en la posición del atacante de $1^{\circ}$ Tiempo y de la zona de finalización del ataque del $2^{\circ}$ Tiempo $(\mathrm{N}=1627)$.

Por último, las variables relativas a la distancia entre jugadores se representaron mediante diagramas de caja (Figuras 8 y 9). La variable Distancia del colocador al atacante de primer tiempo (Distancia Col_1T) se caracteriza porque su mediana coincide con el tercer cuartil $(M e=2)$, con lo que se concluye que el $50 \%$ de los casos se concentraron en los valores 1 y 2. Además se observa la presencia de valores extremos en ambos lados. La variable Distancia del atacante de primer tiempo al atacante de segundo tiempo (Distancia 1T_2T) presenta una mayor dispersión de los datos, siendo el valor de la mediana 1, y concentrándose el $50 \%$ de los datos entre los valores -5 y 3 . No se observa ningún valor extremo para esta variable. 


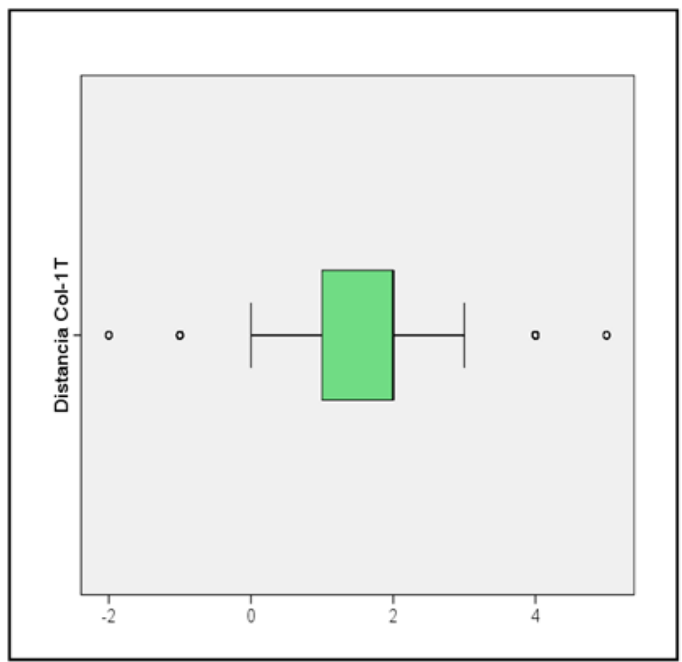

Figura 8. Diagrama de caja de la variable Distancia del colocador al atacante de $1^{\circ}$ tiempo (Distancia Col_1T) $(\mathrm{N}=1627)$.

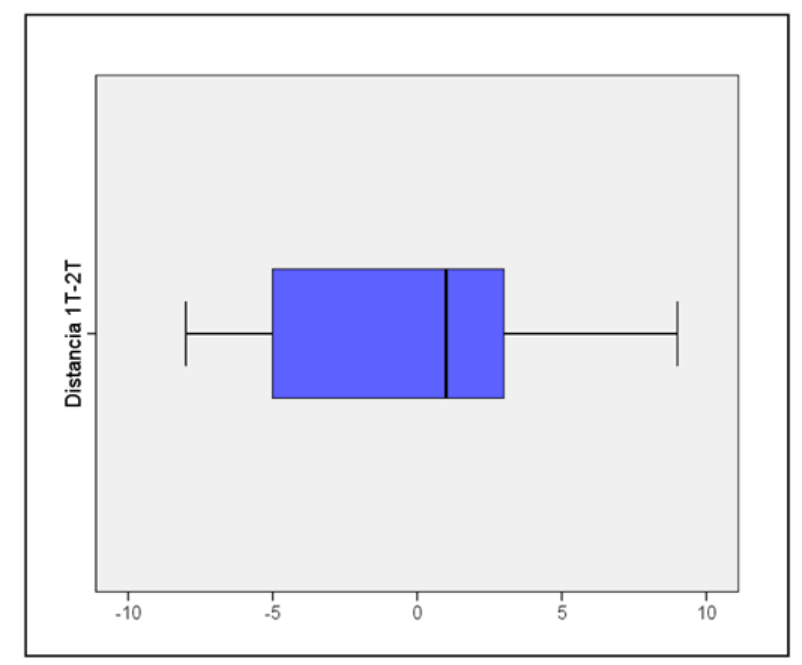

Figura 9. Diagrama de caja de la variable Distancia del atacante de $1^{\circ}$ tiempo al atacante de $2^{\circ}$ tiempo (Distancia 1T_2T) (N=1627).

Las tablas de distribución de frecuencias de todas las variables anteriormente descritas vienen incluidas en el apartado de Anexos.

\section{Estadística inferencial}

En la Tabla 2 se puede observar la correlación establecida entre las variables Latitud Colocación y Latitud ataque $1^{\circ}$ Tiempo. En primer lugar se analizaron las situaciones donde culminó la jugada con el ataque de primer tiempo $(\mathrm{N}=663)$. El valor de $p$ se puede considerar significativo $(p=.000)$, y el tamaño del efecto entre las variables es de 0.565 según el coeficiente de correlación de Rho de Spearman.

Tabla 2. Valores de $p$ y Rho de Spearman entre las variables Latitud Colocación y Latitud atacante $1^{\circ}$ Tiempo en jugadas con ataque de primer tiempo $(\mathrm{N}=663)$.

\begin{tabular}{|c|c|c|c|}
\hline & & Latitud Colocación & Latitud $1^{\circ}$ Tiempo \\
\hline \multirow[t]{3}{*}{ Latitud Colocación } & $\begin{array}{ll}\text { Coeficiente } & \mathrm{de} \\
\text { correlación } & \end{array}$ & 1.000 & $.565^{* * *}$ \\
\hline & Sig. (bilateral) & & .000 \\
\hline & $\mathrm{N}$ & 663 & 663 \\
\hline \multirow[t]{3}{*}{ Latitud $1^{\circ}$ Tiempo } & $\begin{array}{l}\text { Coeficiente } \quad \text { de } \\
\text { correlación }\end{array}$ & $.565^{* *}$ & 1.000 \\
\hline & Sig. (bilateral) & .000 & \\
\hline & $\mathrm{N}$ & 663 & 663 \\
\hline
\end{tabular}


A continuación, se analizaron las jugadas donde se producía un ataque de $2^{\circ}$ tiempo, pero considerando en qué posición el atacante de $1^{\circ}$ tiempo simulaba su acción de ataque (N=1627). Para las variables Latitud (Tabla 3), destaca la asociación entre Latitud Colocación y Latitud ataque $1^{\circ}$ Tiempo, con un valor de $p$ muy significativo $(p<0.01)$ y un coeficiente de correlación de 0.584. Así mismo, las correlaciones entre las variables Latitud Colocación con Latitud ataque $2^{\circ}$ Tiempo y Latitud ataque $1^{\circ}$ Tiempo con Latitud ataque $2^{\circ}$ Tiempo también muestran valores de $p$ significativos $(p<0.01 ; p<0.05)$, aunque el coeficiente de correlación indica un tamaño del efecto considerablemente menor $\left(r_{s}=0.112\right.$; $\left.r_{s}=0.062\right)$.

Respecto a las variables Distancia (Tabla 4), se obtuvo un valor de $p$ muy significativo $(p<0.01)$ entre las variables Distancia Col_1T y Distancia $1 T \_2 T$, con una correlación de tipo inversa, aunque con un tamaño del efecto moderado $\left(r_{s}=-0.255\right)$.

Tabla 3. Valores de $p$ y Rho de Spearman entre las variables Latitud en jugadas con ataque de segundo tiempo (N=1627)

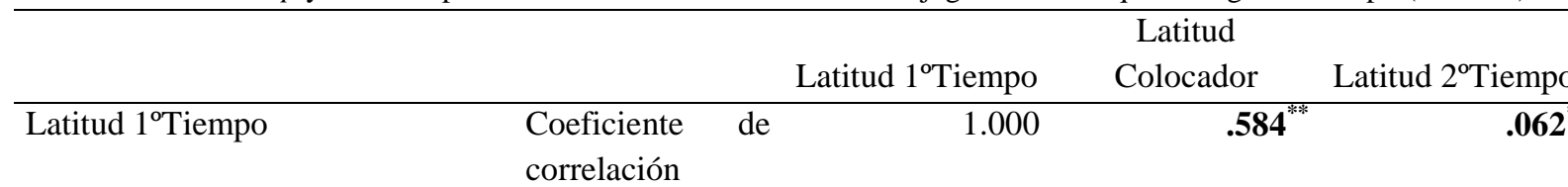

Sig. (bilateral)

.000

.012

$\mathrm{N}$

1627

1627

1627

Latitud Colocador

Coeficiente de
correlación

$.584^{* *}$

1.000

$.112^{\text {*** }}$

Sig. (bilateral)

.000

.000

$\mathrm{N}$

1627

1627

1627

Latitud $2^{\circ}$ Tiempo

Coeficiente $\mathrm{d}$
correlación

$.062^{*}$

$.112^{*}$

1.000

Sig. (bilateral)

.012

.000

$\mathrm{N}$

1627

1627

1627

\footnotetext{
**. La correlación es significativa al nivel 0,01 (bilateral).

*. La correlación es significativa al nivel 0,05 (bilateral).
} 
Tabla 4. Valores de $p$ y Rho de Spearman entre las variables Distancia en jugadas con ataque de segundo tiempo (N=1627)

\begin{tabular}{|c|c|c|c|}
\hline & & Distancia Col_1T & Distancia 1T_2T \\
\hline \multirow[t]{3}{*}{ Distancia Col_1T } & $\begin{array}{l}\text { Coeficiente } \\
\text { correlación }\end{array}$ & 1.000 & $-.255^{* *}$ \\
\hline & Sig. (bilateral) & & .000 \\
\hline & $\mathrm{N}$ & 1627 & 1627 \\
\hline \multirow[t]{3}{*}{ Distancia 1T_2T } & $\begin{array}{l}\text { Coeficiente } \\
\text { correlación }\end{array}$ & $-.255^{* *}$ & 1.000 \\
\hline & Sig. (bilateral) & .000 & \\
\hline & $\mathrm{N}$ & 1627 & 1627 \\
\hline
\end{tabular}

**. La correlación es significativa al nivel 0,01 (bilateral).

En línea con las correlaciones presentadas arriba, en las Figuras 10 y 11 se puede observar la relación entre el pasillo de ataque y las variables de distancia. Así pues, en la Figura 10 vemos como las zonas 2 y 4 presentan una frecuencia de casos más elevada (400) cuando el primer tiempo se ubica entre uno y dos metros por delante del colocador. De manera diferente se comporta la variable Distancia del atacante de $1^{\circ}$ tiempo al atacante de $2^{\circ}$ tiempo, ya que cuando el pasillo de ataque son zonas 2 y 4 la distancia entre ambos más frecuente es de 3 a 5 metros estando el atacante de segundo tiempo por delante, o de 4 a 6 metros estando por detrás.

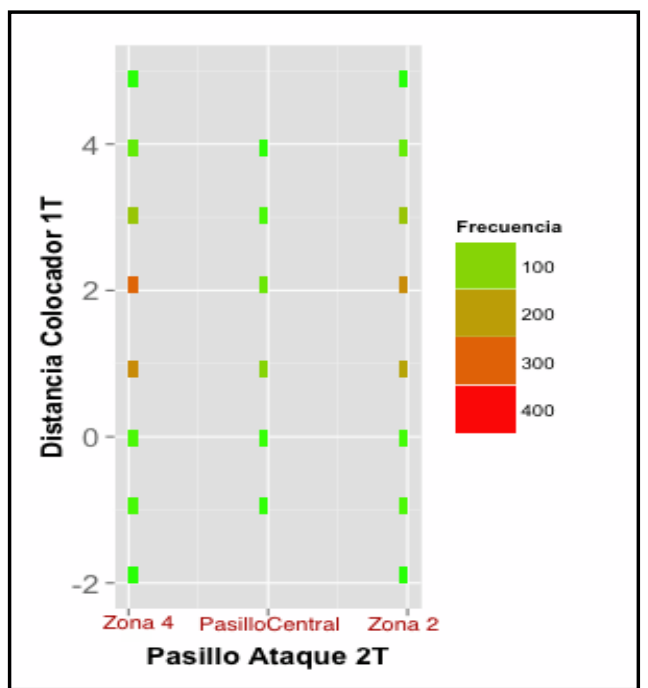

Figura 10. Relación entre las frecuencias del Pasillo de ataque de $2^{\circ}$ tiempo y la Distancia entre el colocador y el atacante de $1^{\circ}$ tiempo.

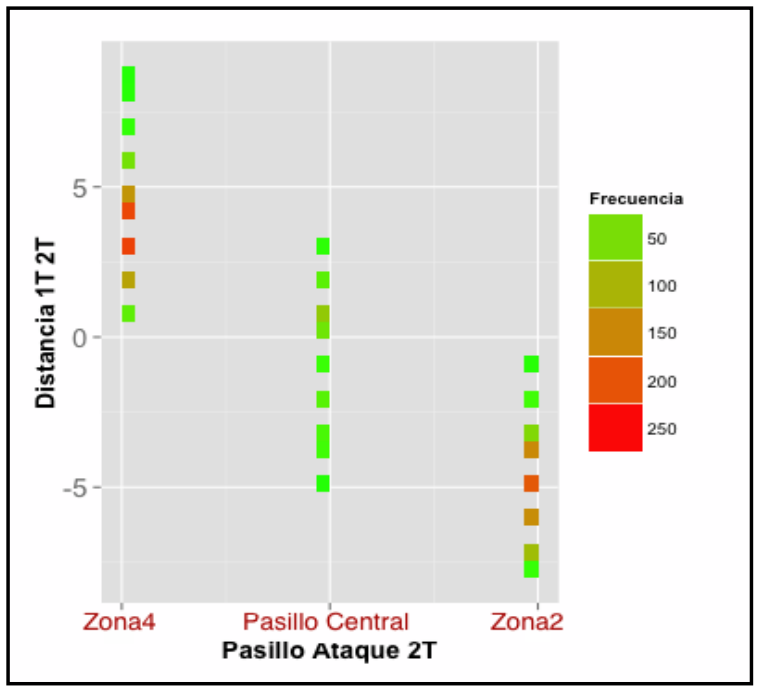

Figura 11. Relación entre las frecuencias del Pasillo de ataque de $2^{\circ}$ tiempo y la Distancia entre el colocador y el atacante de $1^{\circ}$ tiempo. 
En cuanto al análisis multivariante, se eligió el modelo de árbol EVTREE, que fue validado mediante la técnica de Validación Cruzada 10-fold. La media del total de las diez iteraciones que se obtuvo fue de 0.98 (Tabla 5), cifra muy cercana al valor máximo y óptimo (1), con lo que se justifica la elevada calidad del modelo desarrollado. Así mismo, en la Tabla 5 también se observa la matriz de confusión del árbol generado. En la Tabla 6 se presentan los porcentajes de error de clasificación para cada nodo hijo.

Tabla 5. Matriz de confusión del EVTREE y valor de la media tras la Validación cruzada 10 -fold.

\begin{tabular}{lccc}
\hline & Zona 4 & Pasillo Central & Zona 2 \\
\hline Zona 4 & 753 & 31 & 0 \\
\hline Pasillo Central & 9 & 153 & 6 \\
\hline Zona 2 & 0 & 27 & 648 \\
\hline & & MEDIA : 0,98421746 \\
\hline
\end{tabular}

\begin{tabular}{|c|c|}
\hline Nodo & $\%$ Error \\
\hline 4 & 3.8 \\
\hline 6 & 18.2 \\
\hline 7 & 9.2 \\
\hline 8 & 5.1 \\
\hline 11 & 3.7 \\
\hline 12 & 7.4 \\
\hline 13 & 0.0 \\
\hline
\end{tabular}

En la Figura 12 se muestra el árbol de clasificación EVTREE en que se incluyeron las variables Distancia Col_1T y Distancia $1 T \_2 T$ como independientes, y la variable Pasillo de Ataque de $2^{\circ}$ Tiempo como variable dependiente. El árbol contiene un total de seis nodos internos y siete nodos terminales. Como nodo raíz del árbol se observa la variable Distancia Col_1T, por tanto es la que mayor fuerza predictiva presenta, y se subdivide en dos nodos: Nodo 2 cuando Distancia Col_1T $<3$ y Nodo 9 cuando Distancia Col_1T $\geq 3$. En el Nodo 2 se concentra un $75.47 \%$ del total de los casos, mientras que en el Nodo 9 un $24.52 \%$.

Observando los porcentajes de los nodos hijos derivados del Nodo 2, el número de casos más elevado se concentra en el Nodo 8 , con un $37 \%$ del total de las jugadas, donde prevalece claramente el ataque por la zona 4 . A este nodo le sigue el Nodo 4, con un $29.13 \%$ de casos, siendo en este caso el pasillo de ataque más utilizado el de zona 2. Respecto a la zona 2 de ataque, aunque con pocos casos $(n=11,0.67 \%)$, el Nodo 6 confirma que el ataque de segundo tiempo se concentra en dicha zona cuando el central está por detrás del colocador (Distancia Col_1T<0). No obstante, los resultados más relevantes del Nodo 2 se concentran en el Nodo 7, donde se observa la acumulación de la mayoría de casos de ataque de segundo tiempo por el Pasillo Central $(8.66 \%, \mathrm{n}=141)$, concretamente cuando Distancia Col_1T<3 y $\geq 0$.

Por otro lado, en cuanto a los nodos hijos del Nodo 9, se observa que el porcentaje de jugadas en los nodos 11 y 13 es prácticamente idéntico (11.67\% y $11.18 \%$ respectivamente), con un claro predominio en cada uno de ellos de las zonas 2 y 4 . Además, gracias al Nodo 12, se puede afirmar que el ataque por el pasillo central tiene muy poca presencia cuando la Distancia Col_1T $\geq 3$, ya que el porcentaje de jugadas que acumula dicho nodo es de $1.65 \%$. 
Relación entre la posición del atacante de primer tiempo y del colocador y su influencia en la zona de ataque en voleibol masculino de élite

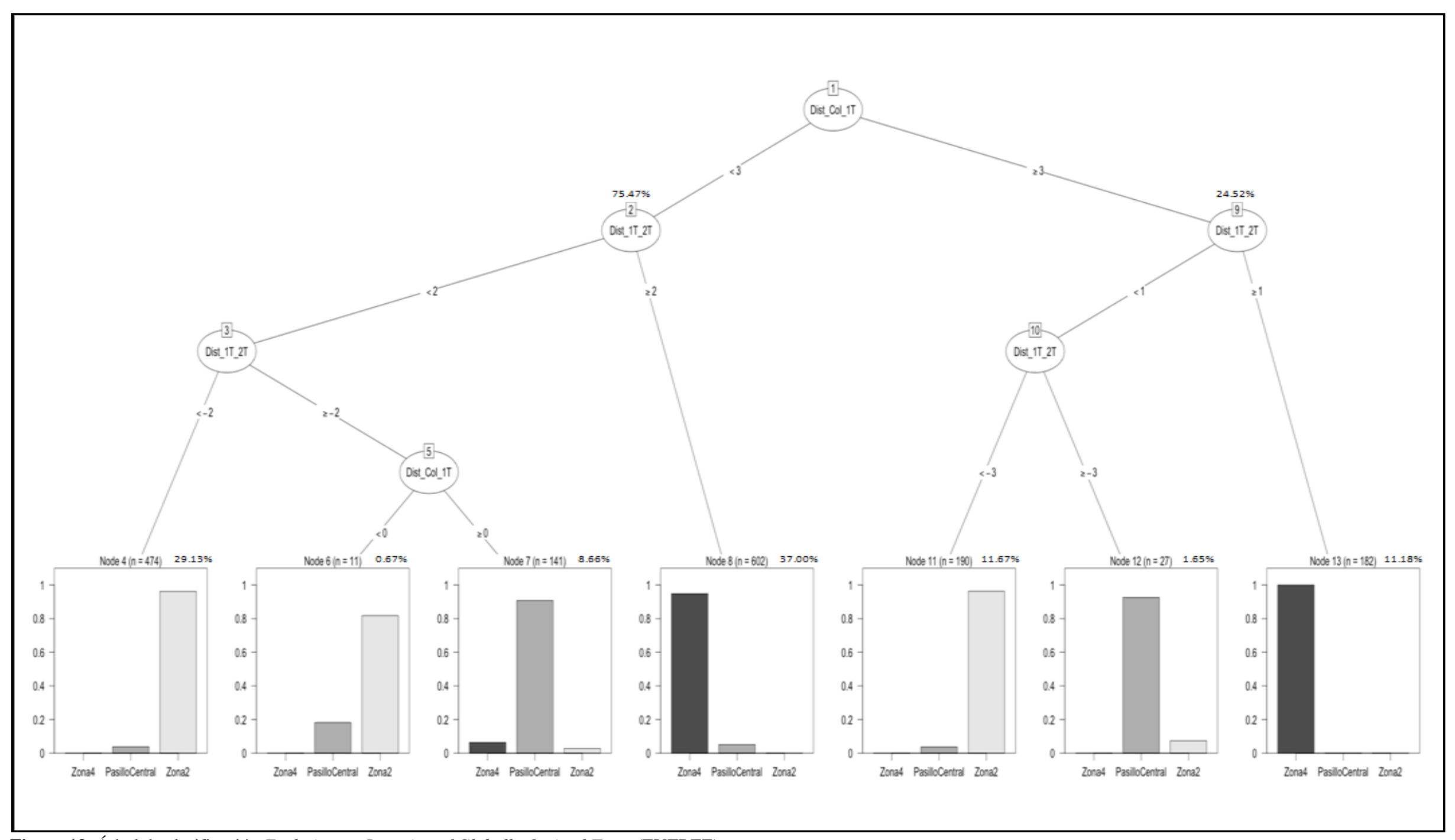

Figura 12. Árbol de clasificación Evolutionary Learning of Globally Optimal Trees (EVTREE). 


\section{Discusión}

El objetivo principal de este estudio fue determinar si existía una relación entre la posición del atacante de primer tiempo respecto al colocador y respecto al atacante de segundo tiempo, con el pasillo de ataque de segundo tiempo. Los resultados de este estudio sugieren que existe una relación significativa entre la posición del atacante de primer tiempo y la del colocador en $\mathrm{K} 1$, independientemente de si ocurre o no ataque de primer tiempo. Desde un punto de vista dinámico, se observó que la posición del atacante de primer tiempo varía acorde con la del colocador, normalmente a una distancia de uno o dos metros por delante. Además, la variable Distancia del colocador al atacante de primer tiempo aparece como principal predictora del pasillo de ataque de segundo tiempo, puesto que éste se ejecuta por el Pasillo Central cuando el atacante de primer tiempo está uno o dos metros por delante del colocador. Estos resultados ponen de manifiesto que las estrategias ofensivas de los equipos de élite masculinos en K1 se caracterizan por la cercanía del atacante de primer tiempo respecto al colocador y principalmente por delante de éste, independientemente del tipo de ataque que se ejecute, constituyendo dicha distancia un fuerte predictor de la zona de ataque de segundo tiempo, concretamente para determinar cuándo se utiliza el pasillo central.

En referencia a la disponibilidad del atacante de primer tiempo en $\mathrm{K} 1$, cabe destacar que existe un claro predominio de jugadas en que el atacante de primer tiempo está disponible, lo cual se justifica gracias a las características principales de esta fase del juego: la estabilidad y la baja interferencia contextual (Castro et al., 2011; Castro y Mesquita, 2008). Además, se observó que el ataque de segundo tiempo es el más utilizado en situaciones de $\mathrm{K} 1$, incluso con la disponibilidad del atacante de primer tiempo, coincidiendo con los resultados de Afonso et al. (2005). En cuanto al pasillo de ataque de segundo tiempo, se observa un claro predominio de las zonas 4 y 2 , en detrimento del pasillo central, donde el ataque lo realiza un cuarto jugador zaguero que se incorpora a las estrategias ofensivas del equipo.

En estudios previos como el de Marcelino et al. (2014), se estudiaron las posiciones del colocador y del atacante de primer tiempo como predictores de la zona de finalización de ataque. No obstante, en la literatura científica hasta el momento se han medido las posiciones de los jugadores desde un punto de vista estático e independiente, sin tomar en consideración que la variabilidad en la posición del colocador puede determinar la posición del atacante de primer tiempo. Esto último se relaciona con el concepto de secuencialidad en las acciones de voleibol, es decir cómo las acciones previas (posición del colocador) influyen sobre las posteriores (posición del atacante de primer tiempo) (Lames y McGarry, 2007; Mesquita, 2005). Este estudio aporta una nueva perspectiva en la visión de la relación espacial colocador- atacante de primer tiempo, considerando el carácter dinámico en las posiciones de ambos. Ello significa que se ha analizado la posición del atacante de primer tiempo en función de la distancia que le separa del colocador a partir de las distintas posiciones en que se ha ubicado éste último. 
En referencia a las zonas (latitud) donde más se ubicaron las acciones de estos dos jugadores, se observó que en las zonas 5, 6 y 7 ocurren un alto porcentaje de acciones de colocación, y en las zonas 4 y 5 es donde más veces el atacante de primer tiempo simula un ataque. Por tanto, los resultados de este estudio confirman que la zona 6 sigue siendo en voleibol la zona más habitual de colocación, tal como describía Beal (1992). En cuanto a la zona más habitual del atacante de primer tiempo, se reafirma lo que otros estudios ya evidenciaron (Costa et al., 2010; Marcelino et al., 2014), ya que las latitudes 4 y 5 se corresponden con la zona 3 a que se refieren dichos autores. Ahora bien, la aportación del presente estudio en comparación con los citados deriva de la mayor precisión aportada por las variables Latitud y Distancia, pudiendo de tal forma discriminar de manera más concreta la ubicación de los jugadores en el campo, así como el espacio entre cada uno de ellos.

La distancia existente entre el colocador y el atacante de primer tiempo permitió concluir que en la mayoría de las jugadas, el atacante de primer tiempo se ubicaba a $1 \mathrm{o}$ 2 metros por delante del colocador, lo cual corrobora las zonas con más prevalencia para cada jugador descritas previamente. Por otro lado, la distancia entre el colocador y el atacante de primer tiempo se correlaciona negativamente con la distancia entre los atacantes de primer y segundo tiempo, esto es, cuanto más cerca está el atacante de primer tiempo del colocador, más lejos el uno del otro estarán el atacante de primer y de segundo tiempo. Esta asociación encuentra su lógica en el resto de resultados, ya que como se ha visto el atacante de primer tiempo tiende a desplazarse cerca del colocador (zonas centrales del campo) y los ataques de segundo tiempo se ejecutan habitualmente en las zonas de los extremos.

En cuanto a la incorporación del atacante de segundo tiempo en la ofensiva de los equipos, resulta esencial recordar que en voleibol, el uso de combinaciones de ataque es fundamental para aumentar el éxito (Marcelino et al., 2008), sobre todo en K1 ya que se trata de la situación más estable para los equipos. Así pues, el hecho de conocer las tendencias de ataque en función de donde se ubica cada uno de los jugadores implicados en la construcción de la ofensiva (colocador, atacante de primer tiempo y atacante de segundo tiempo), constituye un aspecto de especial interés para la organización en la defensa del equipo rival. Esto es así debido al desequilibrio existente entre los equipos en K1 y en defensa a favor del primero (Palao, Santos y Ureña, 2002; Ureña, 1998). La principal causa de ello es el déficit de tiempo para el equipo en defensa, generado por parte del equipo en $\mathrm{K} 1$ mediante el uso de distintas estrategias ofensivas: tiempos rápidos de ataque, combinaciones, aumento en el número de atacantes, incorporación de atacantes zagueros, etc. (Palao et al., 2005). Por tanto, identificar factores derivados de la posición del atacante de primer tiempo y el colocador que se relacionen con la zona de finalización de ataque, se convierte en un tema central a la hora de que los equipos organicen su estrategia defensiva, y que de este modo el equipo en defensa sea capaz de contrabalancear su equilibrio con el equipo en K1. 
A partir de aquí, la Distancia del colocador al atacante de primer tiempo se mostró como la variable más predictora del pasillo de ataque de segundo tiempo. En un $75.47 \%$ de las jugadas el atacante de primer tiempo se movió entre uno y dos metros por delante del colocador o por detrás de él (aunque en muy pocas jugadas), mientras que solamente en un $24.52 \%$ se movió tres o más metros por delante. Estos porcentajes incluso superan los obtenidos en el estudio de Marcelino et al. (2014), quienes comprobaron que en casi un $60 \%$ de las jugadas el atacante de primer tiempo se movió cerca del colocador, y sólo en un $16.4 \%$ se movió lejos.

Cuando el atacante de primer tiempo se movió lejos del colocador, las zonas de finalización de ataque fueron las zonas 2 y 4 indistintamente, minimizando la probabilidad de ataque por el pasillo central. En cambio, si el atacante de primer tiempo se movía a dos metros o menos del colocador se observaba una mayor probabilidad de modelos en los que predominaba el ataque por 4. Además, cuando el atacante de primer tiempo simulaba un ataque justo en el primer y segundo metro por delante del colocador, el pasillo central se presentaba como la zona principal de ataque de segundo tiempo. De este modo, se confirma que cuando los equipos de alto nivel utilizan el pasillo central para jugar un ataque de segundo tiempo, lo hacen acumulando su ofensiva en las zonas más céntricas del campo. La relevancia de esto último radica en que, se puede asumir como factor clave la posición del atacante de primer tiempo respecto al colocador, ya que permite descartar o no la colocación al pasillo central de segundo tiempo. La discriminación de estos factores resulta especialmente interesante para el bloqueo rival, dado el déficit de tiempo al que el equipo en defensa está sometido. Así pues, en esta última situación la cercanía entre ambos atacantes ayuda a que el atacante de primer tiempo trate de fijar a su bloqueador central, y que así el atacante de segundo tiempo pueda atacar sin ningún bloqueo (Marcelino et al., 2014). Por otro lado, cuando el atacante de primer tiempo se ubica a más de dos metros por delante del colocador, la presión en cuanto al espacio a recorrer por los bloqueadores se incrementa con respecto a las situaciones en las que el primer tiempo está situado a uno o dos metros por delante del colocador.

\section{Futuras líneas, ventajas y limitaciones}

En futuros estudios sería interesante llevar a cabo la búsqueda de algún tipo de relación entre los distintos modelos de ataque generados en este estudio y el éxito, incluso discriminando según los momentos del juego. Así mismo, distinguir los resultados del presente estudio por equipos o por clasificación de los equipos en el ranking de la competición, podría ayudar a descubrir tendencias propias de cada una de las selecciones nacionales, identificando si estos factores son indicadores del estilo de juego o del rendimiento. Por último, estudiar otros niveles competitivos u otros campeonatos posteriores para realizar comparaciones con la muestra de este estudio se presenta como un nuevo objetivo de gran interés.

La precisión en la medida de las zonas en que se ubican los jugadores dota al estudio de una gran consistencia a la hora de determinar de manera más exacta no sólo 
cada acción del juego, sino también el espacio existente entre los jugadores en cuestión. El instrumento VASports ha permitido avanzar en la precisión de variables espaciales en la metodología observacional aplicada a este tipo de trabajos.

En cuanto al análisis de los datos de este estudio, se ha optado por emplear nuevas técnicas basadas en la minería de datos como son los árboles de clasificación. Este tipo de modelos aportan un enfoque innovador poco presente en el área del análisis del rendimiento deportivo en voleibol. Aún así, hay que admitir que el proceso de preprocesamiento de los datos (filtrado, gestión de casos perdidos y de casos nulos, etc.) puede conllevar a la pérdida de datos o comisión de errores que alteren los resultados.

\section{Conclusiones}

Este estudio aporta una contribución innovadora en referencia a las relaciones espaciales entre jugadores en voleibol, ya que analiza el dinamismo de las posiciones de los jugadores para buscar relaciones entre ellas. La visión dinámica en la relación espacial entre el atacante de primer tiempo y el colocador, constituye la aportación más relevante del presente estudio. Concretamente, en el voleibol de élite masculino el atacante de primer tiempo se mueve predominantemente entre uno y dos metros por delante del colocador, aunque éste varíe su ubicación.

La capacidad del modelo predictivo de este estudio ha permitido identificar la variable Distancia del colocador al atacante de primer tiempo como un predictor del pasillo de ataque de segundo tiempo. En concreto, el pasillo central se utilizaba principalmente cuando el atacante de primer tiempo estaba entre uno o dos metros por delante del colocador, pero cuando se ubicaba a más de dos metros por delante, equilibraba el modelo predominante de ataques por zonas 2 y 4 .

\section{Aplicaciones}

A partir de aquí se evidencia que las estrategias ofensivas de los equipos de alto nivel consisten fundamentalmente en buscar que el atacante de primer tiempo se mueva cerca del colocador y por delante de éste, lo cual puede ayudar al bloqueo del equipo rival a organizar su estrategia defensiva. En cuanto al equipo en K1 se refiere, el hecho de aumentar el uso del ataque de segundo tiempo por el pasillo central resulta interesante puesto que contribuye a crear mayor presión y déficit de tiempo en el bloqueo rival. Así mismo, la búsqueda de una mayor variedad en las posiciones del atacante de primer tiempo puede ayudar a mejorar la imprevisibilidad del ataque. Por otra parte, se ha dado evidencia a factores (relaciones espaciales) que aportan información relevante para el equipo en defensa. Esto es así debido a que se puede ayudar a predecir la zona de finalización del ataque del equipo en K1 gracias a la distancia entre el atacante de primer tiempo y el colocador. Esto último resulta especialmente útil a la hora de ganar ventaja en la acción de bloqueo. 


\section{Agradecimientos}

Al Ministerio de Ciencia e Innovación, por la financiación del proyecto Sistema Mas Vb de Evaluación Competitiva y Orientación Técnica para la Superliga Española de Voleibol (DEP2011-27503).

A Aurelio, por confiar en todo momento en mis aptitudes, y por su energía y tiempo invertido en guiarme hacia la consecución de mis propósitos.

A José Manuel y Manuel, por sus aportaciones en la parte estadística, sin las cuales este estudio no se habría podido llevar a cabo.

A Elia, Joaquín y Antonio, por compartir todo este proceso de trabajo y ofrecerme su apoyo día a día. 


\section{Referencias}

Afonso, J., y Mesquita, I. (2011). Determinants of block cohesiveness and attack efficacy in high-level women's volleyball. European Journal of Sport Science, 11(1), 69-75.

Afonso, J., Esteves, F., Araújo, R., Thomas, L., y Mesquita, I. (2012). Tactical determinants of setting zone in elite men's volleyball. Journal of sports science $y$ medicine, 11(1), 64.

Afonso, J., Mesquita, I., y Palao, J.M. (2005). Relationship between the tempo and zone of spike and the number of blockers against the hitters. International Journal of Volleyball Research, 8(1), 19-23.

Afonso, J., Mesquita, I., Marcelino, R., y Silva, J. (2010). Analysis of the setter's tactical action in high-performance women's volleyball. Kinesiology, 42(1), 82-89.

Anguera, M., Blanco, A., Losada, J. y Hernández, A. (2000). La metodología observacional en el deporte: conceptos básicos. Lecturas: Educación Física y Deportes. Revista Digital, 24.

Asterios, P., Kostantinos, C., Athanasios, M., y Dimitrios, K. (2009). Comparison of technical skills effectiveness of men's National Volleyball teams. International Journal of Performance Analysis in Sport, 9(1), 1-7.

Beal D. (1992). Combinaciones de Ataque. En Bertucci, B. (Ed.), Guía de Voleibol de la Asociación de Entrenadores Americanos de Voleibol. Barcelona. Paidotribo.

Bergeles, N., Barzouka, K., y Nikolaidou, M. (2009). Performance of male and female setters and attackers on Olympic-level Volleyball teams. International Journal of Performance Analysis in Sport, 9, 141-148.

Bertucci, B. (1979). Championship volleyball. The West Point Sports/Fitness series, 12. West Point NY: Leisure Press.

Castro, J., y Mesquita, I. (2008). Estudo das implicações do espaço ofensivo nas características do ataque no Voleibol masculino de elite. Revista Portuguesa de Ciências do Desporto, 8, 114-125.

Castro, J., Souza, A., y Mesquita, I. (2011). Attack efficacy in volleyball: Elite male teams. Perceptual and Motor Skills, 113, 395-408.

Cohen, J. (1960). A coefficient of agreement for nominal scales. Educational and psychological measurement, 20(1), 37-46. 
Coleman, J. E. (1975). The Relationships Between Serving, Passing, Setting, Attacking and Winning in Men's Volleyball: A Research Project Submitted to the Graduate School in Candidacy for the Degree of Master of Science in Physical Education (Tesis Inédita de doctorado). George Williams College. Aurora University.

Costa, G., Barbosa, R. V., y Gama, J. G. (2013). The modulation of attack on the volleyball High-level: the case of women's Superleague 2011-2012. Revista da Educação Física/UEM, 24(4), 545-557.

Costa, G., Caetano, R., Ferreira, N. N., Junqueira, G., Afonso, J., Costa, R. D., y Mesquita, I. (2011a). Determinants of attack tactics in youth male elite volleyball. International Journal of Performance Analysis in Sport, 11(1), 96-104.

Costa, G., Mesquita, I., Greco, P. J., Ferreira, N. N., y Moraes, J. C. (2010). Relationship between tempo, type and effect of attack in male young volleyball players from in high competitive level. Revista Brasileira de Cineantropometria y Desempenho Humano, 12(6), 428-434.

Costa, G., Mesquita, I., Greco, P. J., Ferreira, N. N., y Moraes, J. C. (2011b). Relação saque, recepção e ataque no voleibol juvenil masculino. Motriz, Rio Claro, 17(1), 11-18.

Fleiss, J. (2003). Statistical methods for rates and proportions. 3rd ed. WileyInterscience.

Grubinger, T., Zeileis, A., y Pfeiffer, K. P. (2014). evtree: Evolutionary Learning of Globally Optimal Classification and Regression Trees in R. Journal of Statistical Software, 61(1).

Hughes, M. D., y Bartlett, R. M. (2002). The use of performance indicators in performance analysis. Journal of sports sciences, 20(10), 739-754.

Lames, M., y McGarry, T. (2007). On the search for reliable performance indicators in game sports. International Journal of Performance Analysis in Sport, 7(1), 62-79.

Marcelino, R., Afonso, J., Moraes, J. C., y Mesquita, I. (2014). Determinants of attack players in high-level men's volleyball. Kinesiology, 46(2), 234-241.

Marcelino, R., Cesar B., Afonso, J., y Mesquita, I. (2008). Attack-Tempo and AttackType as predictors of attack point from opposite players in Volleyball. World Congress of Performance Analysis of Sport VIII, 505. 
Mesquita, I. (2005). A contextualização do treino no voleibol: a contribuição do construtivismo. In D. Araújo (Ed.), O contexto da decisão: a acção táctica no desporto (pp. 355-378). Lisbon, Portugal: Visão e contextos.

Nikos, B., y Elissavet, N. M. (2011). Setter's performance and attack tempo as determinants of attack efficacy in Olympic-level male volleyball teams. International Journal of Performance Analysis in Sport, 11(3), 535-544.

Palao, J. M., Santos, J. A., y Ureña, A. (2004). Effect of team level on skill performance in volleyball. International Journal of Performance Analysis in Sport, 4(2), 50-60.

Palao, J. M., Santos, J. A., y Ureña, A. (2007). Effect of the manner of spike execution on spike performance in volleyball. International Journal of Performance Analysis in Sport, 7(2), 126-138.

Palao, J.M., Santos, J.A., y Ureña, A. (2005). Effect of setter's position on the spike in volleyball. Journal of Human Movement Studies, 48(1): 25-40.

Palao, J.M., Santos, J.A., y Ureña, A. (2002). Incidencia del rendimiento de los complejos de juego por rotaciones sobre la clasificación final de los JJOO de Sydney 2000. In III International Congress on Sport Performance (Valladolid, Spain). Retrieved January (Vol. 12, p. 2002).

Peña, J., Rodríguez-Guerra, J., y Serra, N. (2013). Which skills and factors better predict winning and losing in high-level men's volleyball? The Journal of Strength y Conditioning Research, 27(9), 2487-2493.

Tabachnick, B., y Fidell, L. (2013). Using multivariate statistics (6th ed.). Boston: Allyn y Bacon.

Ureña, A. (1998). La incidencia de la misión ofensiva en el rendimiento de la recepción del saque en voleibol (Tesis Inédita de doctorado). Departamento de personalidad, evaluación y tratamiento psicológico. Universidad de Granada.

Zetou, E., Moustakidis, A., Tsigilis, N., y Komninakidou, A. (2007). Does effectiveness of skill in complex I predict win in men's Olympic volleyball games? Journal of Quantitative Analysis in Sports, 3(4), 1-9. 


\section{Anexos}

Tablas 1, 2 y 3. Análisis de fiabilidad (Intra-observador) de la variable Disponibilidad del atacante de primer tiempo Resumen del procesamiento de los casos

\begin{tabular}{|c|c|c|c|c|c|c|}
\hline & \multicolumn{6}{|c|}{ Casos } \\
\hline & \multicolumn{2}{|c|}{ Válidos } & \multicolumn{2}{|c|}{ Perdidos } & \multicolumn{2}{|c|}{ Total } \\
\hline & $\mathrm{N}$ & Porcentaje & $\mathrm{N}$ & Porcentaje & $\mathrm{N}$ & Porcentaje \\
\hline 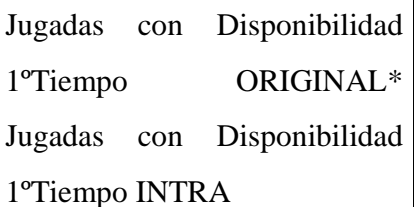 & 394 & $100.0 \%$ & 0 & $0.0 \%$ & 394 & $100.0 \%$ \\
\hline
\end{tabular}

Tabla de contingencia

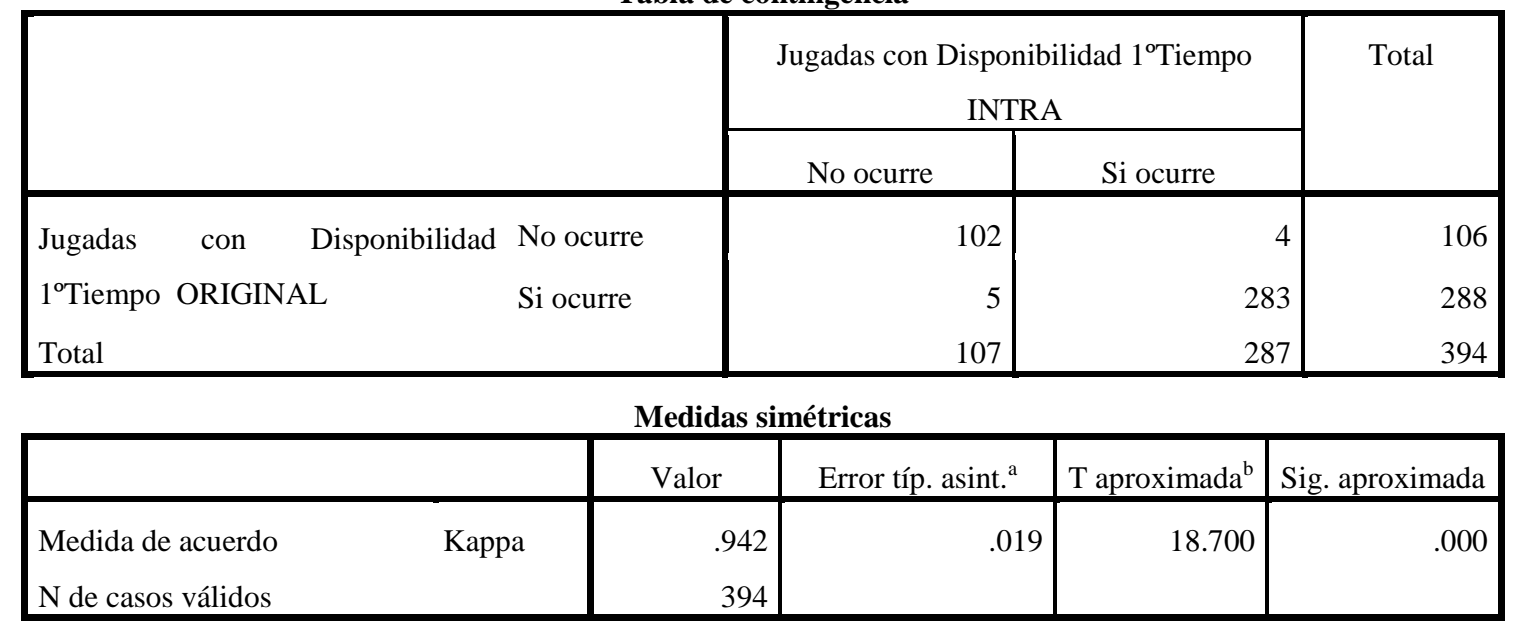
a. Asumiendo la hipótesis alternativa.
b. Empleando el error típico asintótico basado en la hipótesis nula. 
Relación entre la posición del atacante de primer tiempo y del colocador y su influencia en la zona de ataque en voleibol masculino de élite

Tablas 4, 5 y 6. Análisis de fiabilidad (Inter-observador) de la variable Disponibilidad del atacante de primer tiempo Resumen del procesamiento de los casos

\begin{tabular}{|c|c|c|c|c|c|c|}
\hline & \multicolumn{6}{|c|}{ Casos } \\
\hline & \multicolumn{2}{|c|}{ Válidos } & \multicolumn{2}{|c|}{ Perdidos } & \multicolumn{2}{|c|}{ Total } \\
\hline & $\mathrm{N}$ & Porcentaje & $\mathrm{N}$ & Porcentaje & $\mathrm{N}$ & Porcentaje \\
\hline $\begin{array}{l}\text { Jugadas con Disponibilidad } \\
1^{\circ} \text { Tiempo ORIGINAL * } \\
\text { Jugadas con Disponibilidad } \\
1^{\circ} \text { Tiempo INTER }\end{array}$ & 394 & $100.0 \%$ & 0 & $0.0 \%$ & 394 & $100.0 \%$ \\
\hline
\end{tabular}

Tabla de contingencia

\begin{tabular}{|c|c|c|c|c|}
\hline & & \multicolumn{2}{|c|}{$\begin{array}{c}\text { Jugadas con Disponibilidad } 1^{\circ} \text { Tiempo } \\
\text { INTER }\end{array}$} & \multirow[t]{2}{*}{ Total } \\
\hline & & No ocurre & Si ocurre & \\
\hline Jugadas con Disponibilidad & No ocurre & 101 & 5 & 106 \\
\hline $1^{\circ}$ Tiempo ORIGINAL & Si ocurre & 3 & 285 & 288 \\
\hline Total & & 104 & 290 & 394 \\
\hline
\end{tabular}

Medidas simétricas

\begin{tabular}{|lc|r|r|r|r|}
\hline & \multicolumn{1}{|c|}{ Valor } & Error típ. asint. ${ }^{\mathrm{a}}$ & ${\text { T } \text { aproximada }^{\mathrm{b}}}$ & Sig. aproximada \\
\hline Medida de acuerdo & Kappa & .948 & .018 & 18.820 & .000 \\
N de casos válidos & & 394 & & & \\
\hline
\end{tabular}

a. Asumiendo la hipótesis alternativa.

b. Empleando el error típico asintótico basado en la hipótesis nula. 
Tablas 7, 8 y 9. Análisis de fiabilidad (Intra-observador) de la variable Latitud zona de ataque $\left(1^{\circ}\right.$ y $2^{\circ}$ tiempo) Resumen del procesamiento de los casos

\begin{tabular}{|c|c|c|c|c|c|c|}
\hline & \multicolumn{6}{|c|}{ Casos } \\
\hline & \multicolumn{2}{|c|}{ Válidos } & \multicolumn{2}{|c|}{ Perdidos } & \multicolumn{2}{|c|}{ Total } \\
\hline & $\mathrm{N}$ & Porcentaje & $\mathrm{N}$ & Porcentaje & $\mathrm{N}$ & Porcentaje \\
\hline $\begin{array}{l}\text { Latitud Zona ataque }\left(1^{\circ} T y\right. \\
\left.2^{\circ} T\right) \text { ORIGINAL* Latitud } \\
\text { Zona ataque ( } 1^{\circ} T \text { y } \\
\left.2^{\circ} T\right) \\
\text { INTRA }\end{array}$ & 235 & $100,0 \%$ & 0 & $0,0 \%$ & 235 & $100,0 \%$ \\
\hline
\end{tabular}

Tabla de contingencia

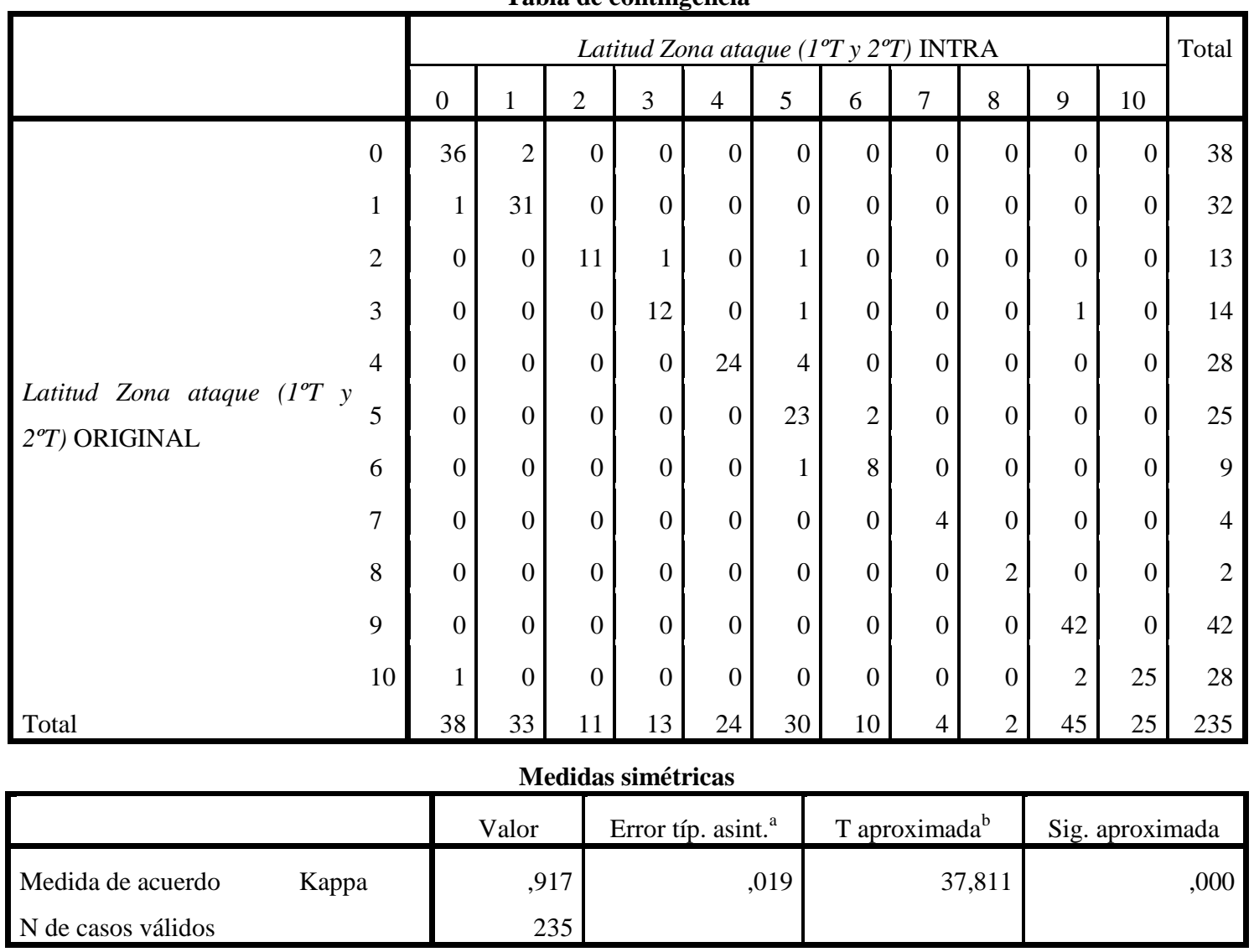

a. Asumiendo la hipótesis alternativa.

b. Empleando el error típico asintótico basado en la hipótesis nula. 
Tablas 10, 11 y 12. Análisis de fiabilidad (Inter-observador) de la variable Latitud zona de ataque ( $1^{\circ}$ y $2^{\circ}$ tiempo)

Resumen del procesamiento de los casos

\begin{tabular}{|c|c|c|c|c|c|c|}
\hline & \multicolumn{6}{|c|}{ Casos } \\
\hline & \multicolumn{2}{|c|}{ Válidos } & \multicolumn{2}{|c|}{ Perdidos } & \multicolumn{2}{|c|}{ Total } \\
\hline & $\mathrm{N}$ & Porcentaje & $\mathrm{N}$ & Porcentaje & $\mathrm{N}$ & Porcentaje \\
\hline $\begin{array}{l}\text { Latitud Zona ataque }\left(1^{\circ} T \text { y } 2^{\circ} T\right) \text { ORIGINAL* } \\
\text { Latitud Zona ataque }\left(1^{\circ} T \text { y } 2^{\circ} T\right) \text { INTER }\end{array}$ & 235 & $100,0 \%$ & 0 & $0,0 \%$ & 235 & $100,0 \%$ \\
\hline
\end{tabular}

Tabla de contingencia

\begin{tabular}{|c|c|c|c|c|c|c|c|c|c|c|c|c|c|}
\hline & & \multicolumn{11}{|c|}{ Latitud Zona ataque $\left(1^{\circ} T\right.$ y $\left.2^{\circ} T\right)$ INTER } & \multirow[t]{2}{*}{ Total } \\
\hline & & 0 & 1 & 2 & 3 & 4 & 5 & 6 & 7 & 8 & 9 & 10 & \\
\hline \multirow{11}{*}{$\begin{array}{l}\text { Latitud } \quad \text { Zona } \\
\text { ataque }\left(1^{\circ} T \quad y\right. \\
\left.2^{\circ} T\right) \\
\text { ORIGINAL }\end{array}$} & 0 & 35 & 3 & 0 & 0 & 0 & 0 & & 0 & 0 & 0 & 0 & 38 \\
\hline & 1 & 2 & 30 & 0 & 0 & 0 & 0 & & 0 & 0 & 0 & 0 & 32 \\
\hline & 2 & 0 & 0 & 11 & 1 & 0 & 1 & & 0 & 0 & 0 & 0 & 13 \\
\hline & 3 & 0 & 0 & 0 & 12 & 0 & 1 & & 0 & 0 & 1 & 0 & 14 \\
\hline & 4 & 0 & 0 & 0 & 0 & 24 & 4 & & 0 & 0 & 0 & 0 & 28 \\
\hline & & 0 & 0 & 0 & 0 & 1 & 22 & & 0 & 0 & 0 & 0 & 25 \\
\hline & 6 & 0 & 0 & 0 & 0 & 0 & 1 & & 0 & 0 & 0 & 0 & 9 \\
\hline & 7 & 0 & 0 & 0 & 0 & 0 & 0 & & 3 & 0 & 0 & 0 & 4 \\
\hline & 8 & 0 & 0 & 0 & 0 & 0 & 0 & & 0 & 2 & 0 & 0 & 2 \\
\hline & 9 & 0 & 0 & 0 & 0 & 0 & 0 & & 0 & 0 & 41 & 1 & 42 \\
\hline & 10 & 1 & 0 & 0 & 0 & 0 & 0 & & 0 & 0 & 2 & 25 & 28 \\
\hline \multicolumn{2}{|l|}{ Total } & 38 & 33 & 11 & 13 & 25 & 29 & 1 & 3 & 2 & 44 & 26 & 235 \\
\hline \multicolumn{14}{|c|}{ Medidas simétricas } \\
\hline & & & & \multicolumn{2}{|c|}{ Valor } & \multicolumn{3}{|c|}{ Error típ. asint. $^{a}$} & T aprox & $\operatorname{mada}^{\mathrm{b}}$ & \multicolumn{3}{|c|}{ Sig. aproximada } \\
\hline \multirow{2}{*}{\multicolumn{2}{|c|}{$\begin{array}{l}\text { Medida de acuerdo } \\
\mathrm{N} \text { de casos válidos }\end{array}$}} & \multicolumn{2}{|c|}{ Kappa } & &, 893 & \multirow{2}{*}{\multicolumn{3}{|c|}{, 022}} & \multirow{2}{*}{\multicolumn{2}{|c|}{36,797}} & \multirow{2}{*}{\multicolumn{3}{|c|}{000}} \\
\hline & & & & & 235 & & & & & & & & \\
\hline
\end{tabular}

a. Asumiendo la hipótesis alternativa.

b. Empleando el error típico asintótico basado en la hipótesis nula. 
Tablas 13, 14 y 15. Análisis de fiabilidad (Intra-observador) de la variable Latitud colocación

\begin{tabular}{|c|c|c|c|c|c|c|}
\hline \multicolumn{7}{|c|}{ Resumen del procesamiento de los casos } \\
\hline & \multicolumn{6}{|c|}{ Casos } \\
\hline & \multicolumn{2}{|c|}{ Válidos } & \multicolumn{2}{|c|}{ Perdidos } & \multicolumn{2}{|c|}{ Total } \\
\hline & $\mathrm{N}$ & Porcentaje & $\mathrm{N}$ & Porcentaje & $\mathrm{N}$ & Porcentaje \\
\hline $\begin{array}{l}\text { LAT_COL } \\
\text { INTRA_LAT_COL }\end{array}$ & 235 & $100.0 \%$ & 0 & $0.0 \%$ & 235 & $100.0 \%$ \\
\hline
\end{tabular}

Tabla de contingencia

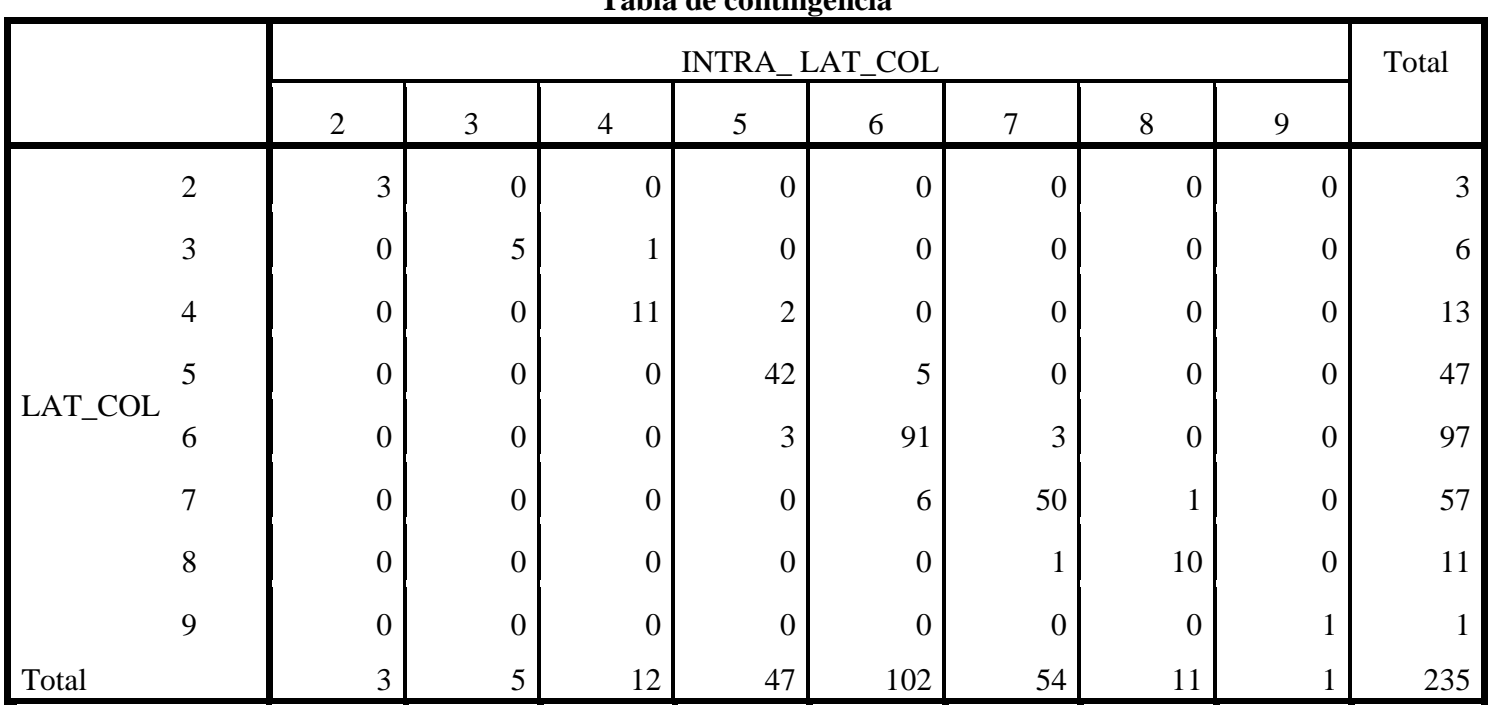

Medidas simétricas

\begin{tabular}{|lc|r|r|r|r|}
\hline & \multicolumn{1}{|c|}{ Valor } & Error típ. asint. & T aproximada $^{\mathrm{b}}$ & Sig. aproximada \\
\hline Medida de acuerdo & Kappa & .870 & .027 & 23.628 & .000 \\
N de casos válidos & & & & \\
\hline
\end{tabular}

a. Asumiendo la hipótesis alternativa.

b. Empleando el error típico asintótico basado en la hipótesis nula. 
Tablas 16, 17 y 18. Análisis de fiabilidad (Inter-observador) de la variable Latitud colocación

\begin{tabular}{|c|c|c|c|c|c|c|}
\hline \multicolumn{7}{|c|}{ Resumen del procesamiento de los casos } \\
\hline & \multicolumn{6}{|c|}{ Casos } \\
\hline & \multicolumn{2}{|c|}{ Válidos } & \multicolumn{2}{|c|}{ Perdidos } & \multicolumn{2}{|c|}{ Total } \\
\hline & $\mathrm{N}$ & Percent & $\mathrm{N}$ & Percent & $\mathrm{N}$ & Percent \\
\hline $\begin{array}{l}\text { LAT_COL } \\
\text { INTER_LAT_COL }\end{array}$ & 235 & $100.0 \%$ & 0 & $0.0 \%$ & 235 & $100.0 \%$ \\
\hline
\end{tabular}

Tabla de contingencia

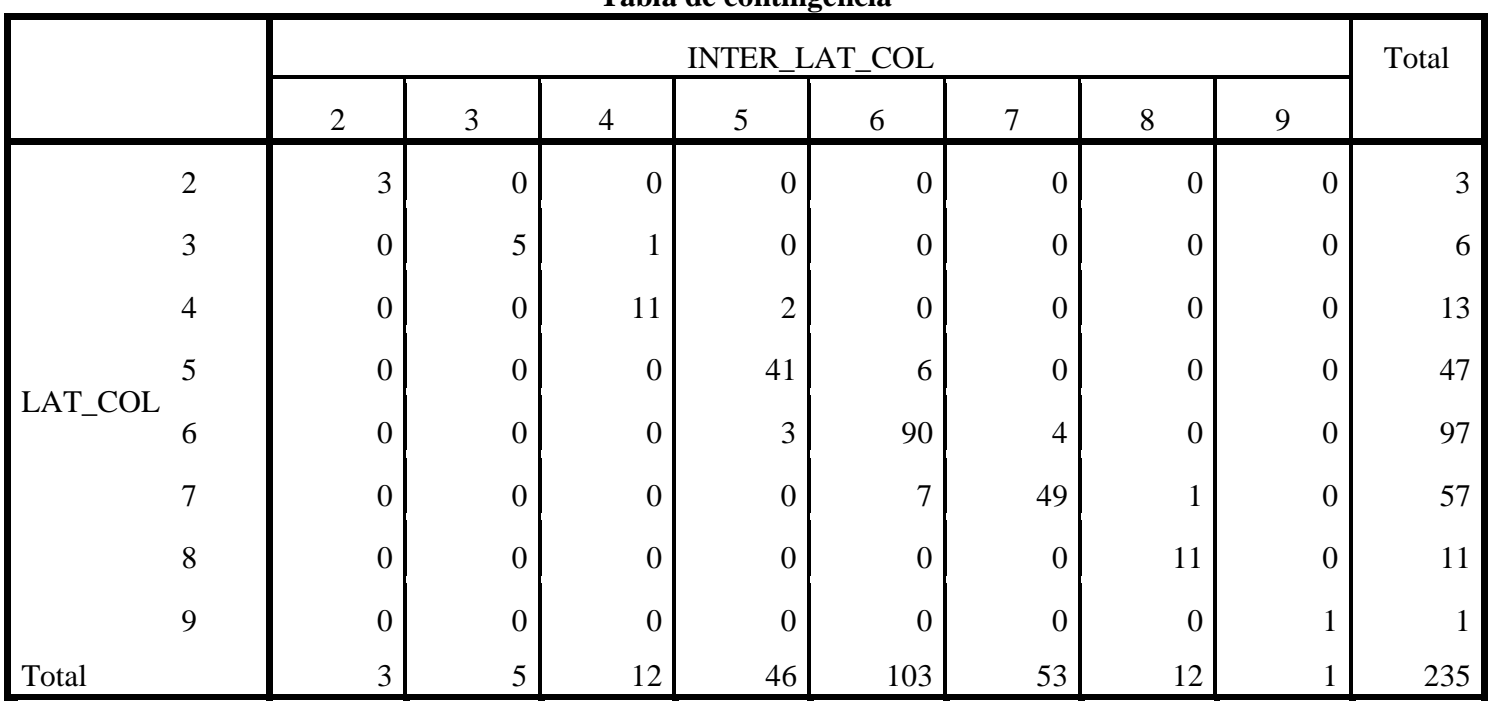

Medidas simétricas

\begin{tabular}{|lc|r|r|r|r|}
\hline & \multicolumn{1}{|c|}{ Valor } & Error típ. asint. & T aproximada $^{\mathrm{b}}$ & Sig. aproximada \\
\hline Medida de acuerdo & Kappa & .858 & .028 & 23.372 & .000 \\
N de casos válidos & & & & \\
\hline
\end{tabular}

a. Asumiendo la hipótesis alternativa.

b. Empleando el error típico asintótico basado en la hipótesis nula. 
Relación entre la posición del atacante de primer tiempo y del colocador y su influencia en la zona de ataque en voleibol masculino de élite

Tabla 19. Tabla de frecuencias de la variable Disponibilidad del atacante de primer tiempo

\begin{tabular}{|c|c|c|c|c|c|}
\hline \multicolumn{6}{|c|}{ Disponibilidad del atacante de primer tiempo } \\
\hline & & Frecuencia & Porcentaje & Porcentaje válido & $\begin{array}{l}\text { Porcentaje } \\
\text { acumulado }\end{array}$ \\
\hline \multirow[t]{3}{*}{ Válido } & Sí & 1601 & 59,3 & 40,7 & 40,7 \\
\hline & NO & 2335 & 40,7 & 59,3 & 100,0 \\
\hline & Total & 3936 & 100,0 & 100,0 & \\
\hline
\end{tabular}

Tabla 20. Tabla de frecuencias de la variable Tipo de Ataque

\begin{tabular}{|c|c|c|c|c|c|c|}
\hline \multicolumn{7}{|c|}{ Tipo de Ataque } \\
\hline & & & Frecuencia & Porcentaje & Porcentaje válido & $\begin{array}{l}\text { Porcentaje } \\
\text { acumulado }\end{array}$ \\
\hline \multirow[t]{4}{*}{ Válido } & $\begin{array}{l}\text { ATAQUE } \\
\text { COLOCAI }\end{array}$ & & 45 & 1,9 & 1,9 & 1,9 \\
\hline & $\begin{array}{l}\text { ATAQUE } \\
\text { TIEMPO }\end{array}$ & $1^{\mathrm{o}}$ & 663 & 28,4 & 28,4 & 30,3 \\
\hline & $\begin{array}{l}\text { ATAQUE } \\
\text { TIEMPO }\end{array}$ & $2^{\circ}$ & 1627 & 69,7 & 69,7 & 100,0 \\
\hline & Total & & 2335 & 100,0 & 100,0 & \\
\hline
\end{tabular}

Tabla 21. Tabla de frecuencias de la variable Pasillo de ataque segundo tiempo

\begin{tabular}{|c|c|c|c|c|c|}
\hline \multicolumn{6}{|c|}{ Pasillo de ataque segundo tiempo } \\
\hline & & Frecuencia & Porcentaje & Porcentaje válido & $\begin{array}{l}\text { Porcentaje } \\
\text { acumulado }\end{array}$ \\
\hline \multirow[t]{4}{*}{ Válido } & ZONA 4 & 762 & 46,8 & 46,8 & 46,8 \\
\hline & $\begin{array}{l}\text { PASILLO } \\
\text { CENTRAL }\end{array}$ & 211 & 13,0 & 13,0 & 59,8 \\
\hline & ZONA 2 & 654 & 40,2 & 40,2 & 100,0 \\
\hline & Total & 1627 & 100,0 & 100,0 & \\
\hline
\end{tabular}

Tabla 22. Tabla de frecuencias de la variable Latitud Colocación

\begin{tabular}{|c|c|c|c|c|c|}
\hline \multicolumn{6}{|c|}{ Latitud Colocación } \\
\hline & & Frecuencia & Porcentaje & Porcentaje válido & $\begin{array}{l}\text { Porcentaje } \\
\text { acumulado }\end{array}$ \\
\hline \multirow[t]{10}{*}{ Válido } & 1 & 1 &, 1 &, 1 & , 1 \\
\hline & 2 & 7 & ,4 & ,4 &, 5 \\
\hline & 3 & 32 & 2,0 & 2,0 & 2,5 \\
\hline & 4 & 90 & 5,5 & 5,5 & 8,0 \\
\hline & 5 & 298 & 18,3 & 18,3 & 26,3 \\
\hline & 6 & 655 & 40,3 & 40,3 & 66,6 \\
\hline & 7 & 409 & 25,1 & 25,1 & 91,7 \\
\hline & 8 & 115 & 7,1 & 7,1 & 98,8 \\
\hline & 9 & 20 & 1,2 & 1,2 & 100,0 \\
\hline & Total & 1627 & 100,0 & 100,0 & \\
\hline
\end{tabular}


Relación entre la posición del atacante de primer tiempo y del colocador y su influencia en la zona de ataque en voleibol masculino de élite

Tabla 23. Tabla de frecuencias de la variable Latitud ataque $1^{\circ}$ Tiempo

\begin{tabular}{|c|c|c|c|c|c|}
\hline \multicolumn{6}{|c|}{ Latitud ataque $1^{\circ}$ Tiempo } \\
\hline & & Frecuencia & Porcentaje & Porcentaje válido & $\begin{array}{l}\text { Porcentaje } \\
\text { acumulado }\end{array}$ \\
\hline \multirow[t]{10}{*}{ Válido } & 1 & 8 &, 5 & ,5 & ,5 \\
\hline & 2 & 150 & 9,2 & 9,2 & 9,7 \\
\hline & 3 & 311 & 19,1 & 19,1 & 28,8 \\
\hline & 4 & 450 & 27,7 & 27,7 & 56,5 \\
\hline & 5 & 442 & 27,2 & 27,2 & 83,7 \\
\hline & 6 & 210 & 12,9 & 12,9 & 96,6 \\
\hline & 7 & 46 & 2,8 & 2,8 & 99,4 \\
\hline & 8 & 9 & ,6 & ,6 & 99,9 \\
\hline & 9 & 1 &, 1 &, 1 & 100,0 \\
\hline & Total & 1627 & 100,0 & 100,0 & \\
\hline
\end{tabular}

Tabla 24. Tabla de frecuencias de la variable Latitud ataque $2^{\circ}$ Tiempo

\begin{tabular}{|c|c|c|c|c|c|}
\hline \multicolumn{6}{|c|}{ Latitud zona ataque $2^{\circ}$ Tiempo } \\
\hline & & Frecuencia & Porcentaje & Porcentaje válido & $\begin{array}{l}\text { Porcentaje } \\
\text { acumulado }\end{array}$ \\
\hline \multirow[t]{12}{*}{ Válido } & 0 & 324 & 14,1 & 19,9 & 19,9 \\
\hline & 1 & 427 & 18,6 & 26,2 & 46,2 \\
\hline & 2 & 11 &, 5 & ,7 & 46,8 \\
\hline & 3 & 23 & 1,0 & 1,4 & 48,2 \\
\hline & 4 & 88 & 3,8 & 5,4 & 53,7 \\
\hline & 5 & 65 & 2,8 & 4,0 & 57,7 \\
\hline & 6 & 28 & 1,2 & 1,7 & 59,4 \\
\hline & 7 & 7 & ,3 & 4 & 59,8 \\
\hline & 8 & 10 & ,4 & 6 & 60,4 \\
\hline & 9 & 451 & 19,7 & 27,7 & 88,1 \\
\hline & 10 & 193 & 8,4 & 11,9 & 100,0 \\
\hline & Total & 1627 & 71,0 & 100,0 & \\
\hline Perdidos & Sistema & 663 & 29,0 & & \\
\hline Total & & 2290 & 100,0 & & \\
\hline
\end{tabular}


Relación entre la posición del atacante de primer tiempo y del colocador y su influencia en la zona de ataque en voleibol masculino de élite

Tabla 25. Estadística descriptiva de las variables Distancia

\begin{tabular}{|c|c|c|c|}
\hline \multicolumn{4}{|c|}{ Estadísticos } \\
\hline & & $\begin{array}{c}\text { Distancia del } \\
\text { colocador al } \\
1^{\circ} \mathrm{T} \text { (Lat Col- } \\
\text { Lat1T) }\end{array}$ & $\begin{array}{c}\text { Distancia del } \\
1^{\circ} \mathrm{T} \text { al } 2^{\circ} \mathrm{T} \\
\text { (Lat1T- } \\
\text { Lat2T) }\end{array}$ \\
\hline \multirow[t]{2}{*}{$\mathrm{N}$} & Válidos & 1627 & 1627 \\
\hline & Perdidos & 0 & 0 \\
\hline Mediana & & 2 & 1 \\
\hline Mínimo & & -2 & -8 \\
\hline Máximo & & 5 & 9 \\
\hline Percentiles & 25 & 1 & -5 \\
\hline & 50 & 2 & 1 \\
\hline & 75 & 2 & 3 \\
\hline
\end{tabular}

Tabla 26. Valor de la media para el modelo EVTREE tras aplicar la Validación Cruzada 10-fold.

\begin{tabular}{lr}
\hline EVTREE & \\
\hline Iteración & \multicolumn{2}{l}{ Acierto } \\
\hline 1 & 0,9850746 \\
\hline 2 & 1 \\
\hline 3 & 1 \\
\hline 4 & 0,9756098 \\
\hline 5 & 0,9863014 \\
\hline 6 & 0,9833333 \\
\hline 7 & 0,9878049 \\
\hline 8 & 1 \\
\hline 9 & 1 \\
\hline 10 & 0,9240506 \\
\hline Media & $\mathbf{0 , 9 8 4 2 1 7 4 6}$ \\
\hline
\end{tabular}

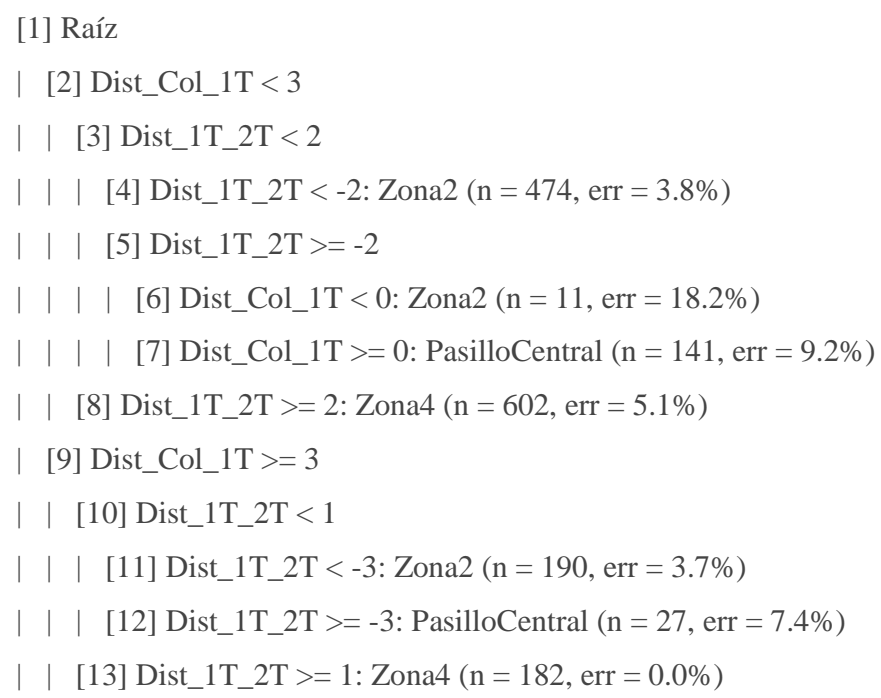

Figura 1. Reglas del árbol y porcentaje de error de clasificación de cada nodo hijo del árbol de clasificación EVTREE. 